\title{
Understanding inter-settlement visibility in Iron Age and Roman Southern Spain with exponential random graph models for visibility networks
}

Tom Brughmans*, Simon Keay, Graeme Earl

Archaeological Computing Research Group, University of Southampton

* Corresponding author: tom.brughmans@uni-konstanz.de

Mailing address: Tom Brughmans, Department of Computer \& Information Science, University of Konstanz, Box 67, 78457 Konstanz, Germany.

Suggested running head: Inter-settlement visibility in Iron Age and Roman Southern Spain

Keywords: Roman Spain, Iberian archaeology, ERGM, network analysis, visibility analysis.

\section{Introduction}

Traditional approaches to the archaeology of Roman Southern Spain have neglected the study of inter-site connections (Keay 1998a; Keay and Earl 2006). The transition from the Iron Age II (ca. $5^{\text {th }}$ c. BC to $3^{\text {rd }}$ c. BC, here referred to as Iberian) to the Roman period (ca. $3^{\text {rd }}$ c. BC to $5^{\text {th }}$ c. AD) is a most striking example of this. Iron Age II and Roman settlements and towns are often investigated independently, which is necessary for a critical understanding of the excavated materials, but it also sidelines the study of ways in which past communities might have interacted and of long-term continuity or discontinuity of occupation.

This paper illustrates how a long-term and large-scale multi-site analysis allows for traditional research themes concerning inter-site connections in Iberian and Roman archaeology to be confronted. It focuses in particular on long-term changes in visibility patterns between urban settlements, a factor considered important for understanding Iberian settlement locations but largely ignored in Roman studies. It further compares these visibility patterns with the location of towns along transport routes, and the Early Imperial urban status of settlements, which are considered key factors for explaining locations of Roman settlements. An exploratory network analysis will reveal similarities and differences in the patterns of visibility networks. 
Hypotheses about the emergence and long-term change of visibility networks will then be tested using Exponential Random Graph Models (ERGMs). In this study we argue that visibility might still have structured interactions between communities in Roman times and should not be dismissed out of hand. However, the way in which it affected human behaviour might have been different in Roman times as compared to the Iron Age. We argue that simulating archaeologists' hypotheses about the emergence of inter-site visibility is a promising way of understanding such differences.

\section{Visibility networks}

\subsection{The study area}

The study area can be more or less equated with the Guadalquivir basin, primarily lying within the modern province of Seville, but also the edges of the adjacent provinces of Córdoba, Huelva and Cádiz, corresponding to the central and western portions of the Roman province of Baetica (Fig. 1). The Guadalquivir river (known as the Baetis in antiquity) cuts through the heart of this area, leaving a landscape of rolling hills behind in Córdoba to meander its way to the Atlantic through an increasingly wide and flat plain (Mayoral Herrera 2004). In antiquity, however, the river mouth was not situated in its current location at the Atlantic coast. Instead it fed into a large inland sea known as the lacus ligustinus south of Seville (Roos et al. 1995), and today referred to as the Marismas. The climate in this part of Southern Spain is hot and dry and can be described as semi-arid. The broadest stretch of the valley on the left bank of the river between Seville and Córdoba, known as the vega and campiña, is a particularly fertile part of the area and was suitable for growing a diversity of crops including grain and olives. The Guadalquivir is flanked by two mountain ranges: the Sierra Morena in the north and the Sistema Sub-bético in the south. The study area and the Sierra Morena in particular are rich in metals such as iron, copper, silver, and lead (Domergue 1990). The direction of the river and the alignment of the mountains give the basin its orientation towards the Atlantic, indicating a greater ease of access to the Atlantic than to the Mediterranean (Cunliffe 1995). This basin with its wide valley flanked by mountains has a funnelling effect on visibility in the landscape: vantage points on the plateau flanks and foothills offer great views across much of the lower lying areas. 
It has been argued that the study of Roman Hispania Ulterior Baetica is dominated on the one hand by a largely ancient historical framework and on the other by highly detailed studies of individual sites or assemblages (Keay 1998a, p. 22). The many historical and epigraphic sources related to key Roman towns like Italica, Hispalis, Gades, and Corduba have dominated scholarship of Roman Baetica. This research tradition has resulted in a picture where most Roman towns are considered similar, while the transition from the Iron Age II period seems to have been an unproblematic break. This is reflected in key publications on the subject: although the province is included in a number of syntheses of Roman Spain (e.g., Le Roux 1995; Richardson 1996), in-depth studies and archaeological syntheses of the province itself are rare (e.g., Keay 1998c). One regional study of particular relevance for this project is the work by Michel Ponsich, who performed large-scale surveys of rural settlements in the Guadalquivir valley, the results of which were published in a number of detailed reports (Ponsich 1974, 1979, 1987, 1991). 


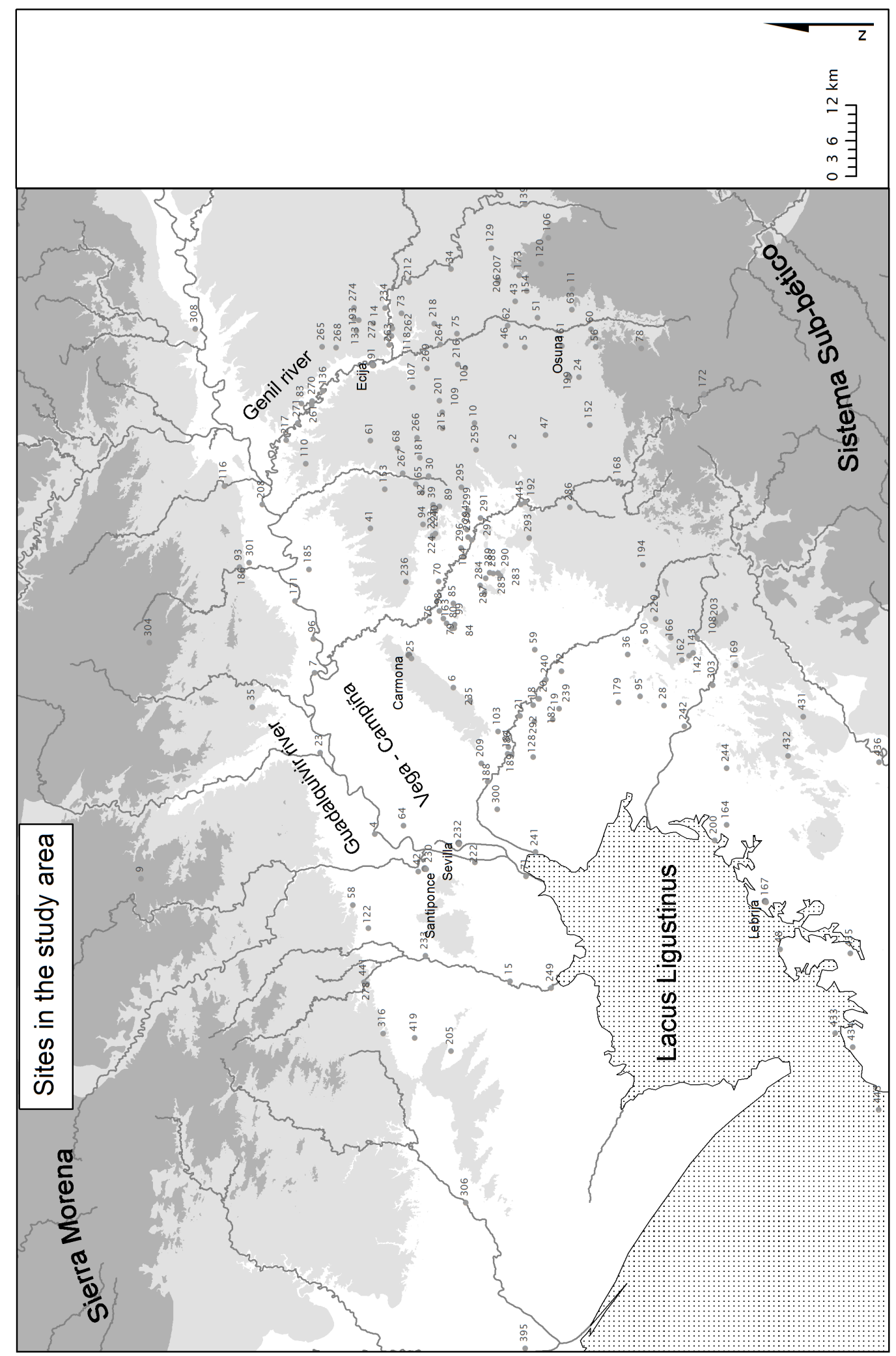

Fig. 1. Sites in the study area and geographical context. A full list of all site names mentioned on this map is included in Appendix A. 


\subsection{Why study visibility networks in Iron Age II and Roman Southern Spain?}

Inter-visibility between settlements, both now and in the past, is high in Southern Spain (Keay 1998b; Keay and Earl 2011). This is a direct result of the landscape and the locations of settlements, positioned mainly along the large rivers or the many hills surrounding the river valleys. In the Iron Age II period, the settlement pattern is generally understood to have consisted of large and often fortified nuclear settlements. These are sometimes referred to by archaeologists as oppida and are frequently surrounded by smaller settlements (Ruiz Rodríguez 1997). While there is considerable debate as to the extent to which these settlements may have acted as political centres and, thus, a town in the Graeco-Roman sense, they are considered as such for the purposes of this research. Many Iron Age settlements of all kinds across Southern Spain as a whole are located on hilltops, terraces or at the edges of plateaus. At some of these sites there is evidence of defensive features and architecture, indicating that these locations were purposefully selected for their defendable nature and the ability to visually control the surrounding landscape, and maybe even for the ability to observe other settlements (Grau Mira 2004; Ruiz Rodríguez and Molinos 1993). It is possible that the patterns of inter-visibility between urban settlements were partly intentionally created and that these patterns had a role to play in structuring the interactions between Iron Age II communities, in other words through the visual control of oppida over surrounding rural settlements or the inter-visibility between settlements required to spread information in a signalling network as has been suggested for the south-east of Spain (Grau Mira 2003, 2005).

There seems to be no reason to believe that inter-visibility was a significant feature between towns in the Roman period (Keay and Earl 2011). Major Roman administrative centres were often located in low-lying areas along the main rivers and roads, to ensure economic and political integration within the wider Roman Empire (Keay 1998b). Due to the continuity in occupation of Iberian settlements, however, the percentage of them to be found on hills and plateau sides is only slightly lower in Roman times than in the Iron Age II period (Fig. 2, Table 1; Keay 1998b), which suggests that visually prominent site locations were not exclusively an Iron Age II phenomenon. This raises a number of questions:

- The trend in Figure 2 suggests that the slight decrease in settlements on hills and plateau sides reflects the degree to which Iron Age II sites continue to be 
occupied in the Roman period. Does the degree of inter-visibility between sites follow the same gentle downward trend through time as a result of this?

- To what extent were visually prominent settlements with Iron Age II origins integrated as towns into the political and economic structure of the Roman Empire? Was this more often the case than with less visually prominent settlements with Iron Age II origins?

- Is there evidence suggesting that inter-visibility of urban settlements was considered less important under the Roman empire? To what degree does the establishment (whether intentionally or not) of inter-visibility patterns differ between the Iron Age II and Roman periods?

In order to address these research questions, a method is needed to analyze both the changing patterns of observed inter-visibility as well as address hypotheses about how these patterns emerged. Very few contemporary accounts exist that could be informative. In De Bello Hispaniensi we read that "Most of the towns in this province are pretty well protected by the mountains, and are situated on natural eminences, so that one has to climb up to reach them, and the approach is thereby made difficult" (10.3) and "Pompeius pitched his camp on the hills, within sight of both towns, but did not venture to come to the help of his own side" (6.2). A quantitative visibility analysis might offer a way forward to shedding light on the significance of these comments.

Archaeologists have often used GIS-based visibility analysis methods for this purpose (Conolly and Lake 2006, p. 225-233; Wheatley and Gillings 2002, p. 201216). They explore the visibility (or not) of landscapes, sites, features and objects to evaluate its possible impact on human behaviour and the probability that visibility patterns were intentionally created. Existing formal approaches, however, rarely analyze hypothetical processes that might have given rise to the observed visibility patterns. A reason for this is no doubt the complex mix of socio-cultural and environmental factors that influenced the establishment of settlement locations: new settlements emerge within an existing cultural landscape; the factors considered important at the emergence of the settlement can rarely be optimised; and the role of settlements and the important factors that accompany them change through time. To claim that inter-visibility of urban settlements was the only factor that determined site location would clearly be risible, but so would the opposite statement that intervisibility played no role at all. In order to test the degree to which the emergence of 
inter-visibility patterns differed through time and make interpretations about the intentional creation of these patterns, an analysis of the structure of observed patterns should be combined with hypothetical models of how these patterns emerged.

In this study we will apply a novel approach based on exploratory network analysis combined with ERGMs. This method allows us to explore the structure of patterns of inter-visibility between sites, the commonalities and differences in the inter-visibility patterns of individual sites, as well as to evaluate hypotheses of how patterns of high or low inter-visibility could have emerged on their own or in relation to a few external attributes. Such a combined approach will allow us to suggest which types of inter-visibility pattern were most or least prominent in each period, whether processes that simulate the emergence (or not) of these particularly common or less common patterns are likely to have led to the observed pattern of each period, and to evaluate the possible importance of inter-visibility for different periods.

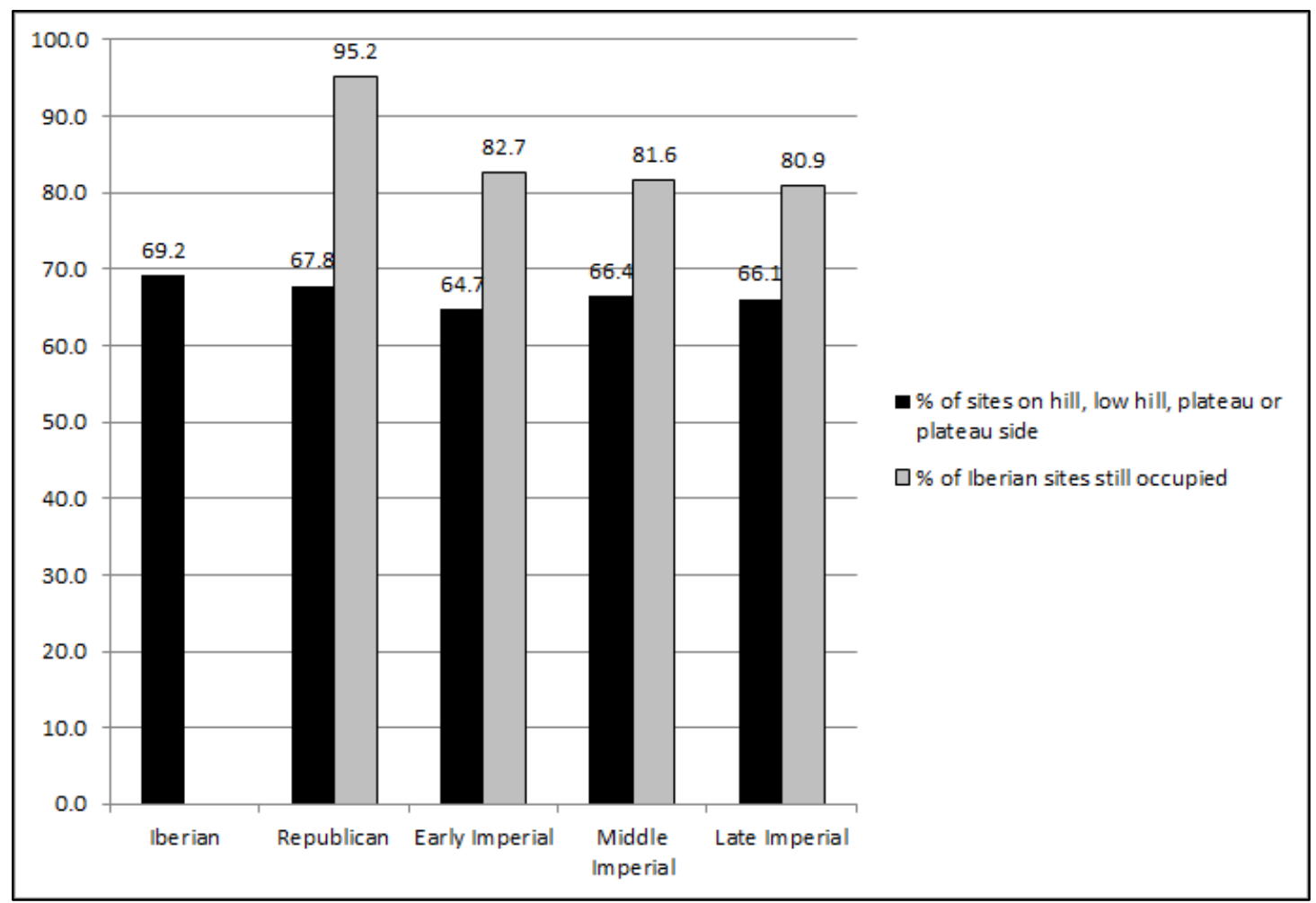

Fig. 2. Proportion of sites per period with a prominent location and with Iberian origins.

Table 1. Number of sites per period and location type.

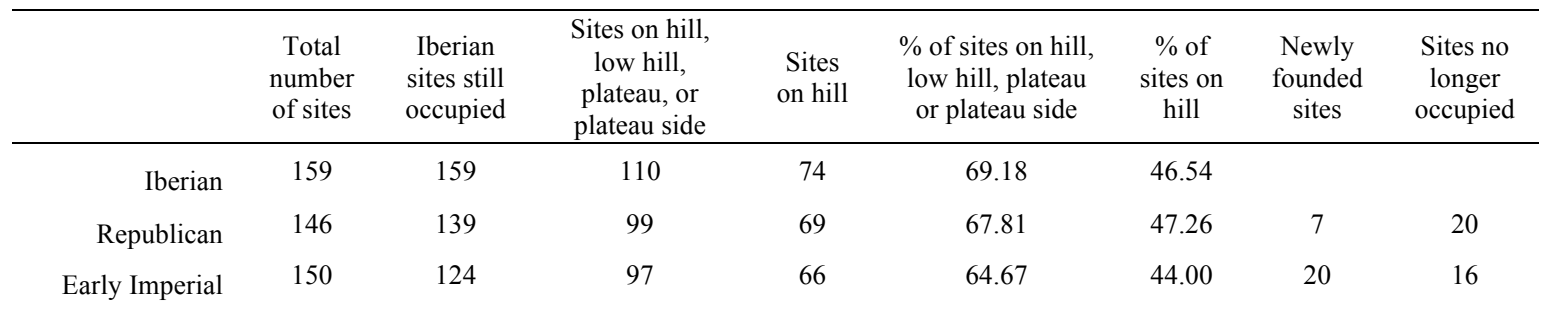




\begin{tabular}{rccccccccc} 
Middle Imperial & 125 & 102 & 83 & 57 & 66.40 & 45.60 & 2 & 27 \\
Late Imperial & 115 & 93 & 76 & 51 & 66.09 & 44.35 & 1 & 11 \\
\hline
\end{tabular}

\subsection{Why processes of emerging inter-visibility?}

Many formal studies of visibility have similar assumptions: they focus on analyzing the structure of visibility patterns to understand their roles and evaluate whether these patterns were intentionally created. In such approaches, the types of inter-visibility patterns that are particularly suitable for a certain purpose such as visual control over a landscape or communication through visible signals, are considered most likely to have been purposefully established. These approaches imply a sequence of events based on the emergence of these particular types of patterns that resulted in the observed structure, a process of changing inter-visibility patterns. In other words, previous studies have assumed that the observed patterns could not have emerged through a random process. A good example of this is Tilley's (1994) study of a network of inter-visibility between barrows on Cranborne Chase, in which an observed network pattern is interpreted as the intentionally established outcome of an untested process: "One explanation for this pattern might be that sites that were particularly important in the prehistoric landscape and highly visible 'attracted' other barrows through time, and sites built later elsewhere were deliberately sited so as to be intervisible with one or more other barrows. In this manner the construction of barrows on Cranborne Chase gradually created a series of visual pathways and nodal points in the landscape" (Tilley 1994, 159).

Very few visibility studies have explored hypotheses about such processes explicitly (see Swanson 2003 for a notable exception). In this study, however, the decisions to establish certain patterns of visibility among urban settlements are the focus of attention. Most crucially, we will try to evaluate to what degree this changed through time, and how this was affected by factors like location along major transport routes or the Early Imperial urban status gained by settlements. The approach taken here is experimental. It will initially focus exclusively on the patterns of intervisibility between settlements, exploring their observed structure as a static snapshot, and then address the following hypothetical question: if the visibility patterning that we have observed was the only reason for selecting the locations of sites, what then would be the process that is most likely to have led to the observed patterning? This 
question will be evaluated through an ERGM approach that models the creation of visibility patterns in abstract space (i.e. by simulating the creation of points and lines without taking the landscape's topography into account as a constraint). These processes will be simulated a second time, incorporating a number of non-visibility factors, such as the urban status of settlements or their location on Roman transport networks, to evaluate whether these factors are important for understanding visibility network creation processes. Finally, the results of this exploratory network analysis and ERGM approach will be re-contextualised within a wider archaeological discussion to shed light on aspects of the changing interactions between urban settlements in the study area through time, as reflected through visibility patterns.

Not including topography as a constraint in our ERGMs is a limitation of this study, because the approach presented here does not allow us to evaluate how common or rare the observed patterns are in this particular landscape. This is only partly overcome in this case study by including the elevation of sites as an attribute in the ERGMs. Instead, the ERGM results show how likely it is that the observed patterns are the outcome of processes that are abstract expressions of archaeologists' hypotheses of visibility network creation (e.g. a tendency to visually control surrounding settlements, or a tendency for inter-visibility). However, within the context of the current study we argue that this abstraction is justified and useful for the following reasons. Firstly, it allows us to express a very wide range of hypothetical processes of network creation in a (relatively) non-computationallyintensive way. It also gives us an idea of which hypothetical processes are less likely to lead to the observed networks, and we believe that it follows that if a process is unlikely to give rise to the observed network in abstract space with no geographical constraints, it will be even less likely to give rise to it in geographical space (although this should be proven in future research). The results will allow us to focus more computationally-intensive modelling efforts with geographical constraints in the future on a more narrow range of processes. Moreover, a method for ERGMs with geographical constraints does not exist yet and will need to be developed in close collaboration with statisticians. Some progress is being made in this direction on which future work could be based, for example by including the distance between pairs of nodes (e.g. Daraganova et al. 2012), or by considering pairs of sites which are not inter-visible in the observed network as 'structural zeros' (pairs of nodes that cannot be connected). The approach advocated here is of course a highly simplistic 
abstraction of complex phenomena. But it has proven an insightful thinking process to evaluate the importance of particular patterns of visibility, and to discard possible but highly unlikely hypotheses.

\subsection{Hypotheses of visibility network creation processes}

The formal method we use requires the past phenomena we are interested in to be abstracted and represented as network data. In this study Iberian settlements and Roman towns are represented as nodes, whilst arcs (directed edges) represent lines of sight from an observer on one site to an observed point at another site (Fig. 3). We can subsequently use these nodes and arcs to construct abstract representations as the outcomes of the hypotheses we are interested in testing. In what follows we will formulate three groups of hypotheses tested in this study, and the abstract network representations we use to identify their expected outcomes (referred to as configurations from now on. The configurations used in the models presented here are shown in figures 3 and 4).

Firstly, we begin with the simplest hypothesis, which is the assumption that lines of sight appear and disappear independently of each other. This reflects a nullhypothesis where no specific configurations of lines of sight have a higher probability of emerging. Such a random process can be simulated with Bernoulli random graph models (Erdös and Rényi 1959). Although such an assumption is unrealistic for visibility networks, it is nevertheless commonly used as a baseline for comparison with the other two groups of models (Koskinen and Daraganova 2013, p. 56).

Secondly, we can formulate a number of hypotheses in which settlements are established where the visibility of other settlements was considered important, but where no other factors are taken into account:

1. If communication or signalling between settlements needed to occur then these need to be inter-visible. This is represented by reciprocal arcs.

2. In order to exert some sort of visual control over surrounding settlements, these need to be visible from a given settlement. This is represented by many outgoing arcs.

3. If a settlement is purposefully visually prominent, it needs to be visible from surrounding settlements. This is represented by many incoming arcs. 
4. If visual isolation is considered important then settlements will be expected to be invisible from surrounding settlements. This is represented by isolated nodes.

Thirdly, a set of hypotheses can be formulated where we take into account the possible importance of other factors (here referred to as site attributes) in the establishment of visibility patterns. These hypotheses also imply certain assumptions about network patterns, this time not just about the configurations of nodes and arcs but also about nodes with certain attributes in interaction. Figure 4 represents different configurations of sites with the four attributes considered here:

1. Iron Age II settlements that continue to be occupied in Roman times could be inter-visible, visually prominent or visually active (i.e., having many outgoing lines of sight).

2. Roman towns with urban status could be inter-visible, visually prominent, or visually active.

3. Roman towns on Roman roads and navigable rivers could be intervisible, visually prominent, or visually active.

4. Sites on hilltops could be inter-visible, visually prominent, or visually active. 


\begin{tabular}{ll} 
Hypothesis & Line of sight \\
\hline Visual isolation & Configuration name in ERGM \\
\hline Inter-visibility & 2-outeciprocity \\
\hline Visual control & 2-out-star \\
\hline 2-in-star
\end{tabular}

Fig. 3. Configurations (network building blocks) used in the models in this study. 


Legend: $\longrightarrow$ Line of sight
Hypothesis
Site with attribute sends arc

Fig. 4. Configurations with attribute effects for binary attributes. In black nodes the attribute is present, and in grey nodes the attribute is either present or not present.

\subsection{Previous archaeological applications of visibility networks}

Although visibility is generally considered an important feature in the study area, little work has been done to formally analyze visibility in Southern Spain (e.g., Garrido González 2011; Mayoral Herrera 2004). Visibility network analyses in archaeology in general are even rarer (early examples include Davidson 1979; Fraser 1983; Tilley 1994) and most of these concern communication networks (e.g., De Montis and Caschili 2012; Shemming and Briggs 2013). Of particular interest for this paper is the work on inter-visibility of Iron Age hillforts in Catalunya by Ruestes Bitrià (2008), who derives an inter-visibility network based on a probable viewshed analysis. Only mutual visibility between hillforts is included and network lines are either present or absent (no reference is made to how the probability of the viewshed results could be included in the network). The inter-visibility network was subsequently analyzed visually. The work of Grau Mira (2003, 2004, 2005) on the continuity and change between Iberian and Roman settlement patterns of Eastern Iberia is also of particular interest. He identified a strong degree of inter-visibility of oppida and argues for the emergence from the sixth century BC onwards of a hierarchical settlement system where oppida visually control surrounding rural 
settlements and access routes. Grau Mira also identified a more dispersed settlement pattern in the late Iron Age as compared to the Classical Iron Age, resulting in a decrease of the number of sites being located in areas that are highly visible from other sites.

The performance of a hypothetical communication network is examined more explicitly by Swanson (2003) in his study of hilltop features around the site of Paquimé (Mexico) that have been interpreted as forming a fire-signalling network. An undirected network of inter-visibility is created by considering only mutually visible sites derived from binary viewsheds. The resulting network is subsequently compared with randomly generated networks by calculating inter-visibility from randomly selected hilltops. The results show a clear difference between the observed network and the random network. The former has no isolated nodes, which is to be expected in an efficient communication network, while the latter networks regularly include isolates. By using such a method Swanson therefore aims to test the likelihood that the observed degree of inter-visibility between features could have arisen by chance.

The current study aims to advocate an alternative approach. It will illustrate how directed networks can be derived from probable viewsheds, which allows for a new range of local network techniques to be applied. Swanson's (2003) use of randomly generated networks as a benchmark will be adopted here and pushed further by applying Exponential Random Graph Models specifically for the study of local patterns.

\subsection{What does inter-visibility mean?}

An incredibly useful formal approach to analyzing inter-visibility between settelements would be merely to consider it a direct result of site locations and the elevations of their surrounding landscapes. This straightforward combination of location and topography is often implied by simple binary viewsheds. But when we aim to understand what it means to be visually prominent this sum can be easily criticized through a range of arguments (for a more in-depth discussion see Wheatley and Gillings 2000; Llobera 2007):

- Spatial experience in a landscape is a complex mix of multi-sensorial information gathering and movement (Tilley 1994). 
- A visibility study implies dominance of vision over the other senses in acquiring knowledge about one's surroundings. This is sometimes considered an imposition of Western biases on the past (Thomas 1993, 2004).

- Geomorphological processes and human actions might cause significant differences between past topographies and the topographical models used. These models themselves are inaccurate abstractions of the modern topography generated through interpolation algorithms selected by the researcher (Fisher 1994; Wheatley and Gillings 2000; Wood 1996).

- Atmospheric conditions and past vegetation affect visibility. Although these often follow cycles they remain very hard to model.

- The ability to identify visible features is dependent on the closeness of the observer to the feature, the object-background clarity, and the observer. Although these are all valid arguments, by no means should they cause archaeologists to abandon their pursuit of understanding past visibility patterns through formal methods altogether. Wheatley and Gillings (2000) argue that these critiques need to be confronted and embraced into formal archaeological visibility studies. The most common answer to these critiques has been to include some form of variability into formal visibility analyses, for example through Higuchi viewsheds (Wheatley and Gillings 2000), fuzzy viewsheds (Fisher 1992), probable viewsheds (Fisher 1994; used here and discussed in more detail in section 4.1 below), the selection of multiple viewing points on a single site (e.g., Mitcham 2002), or cumulative viewsheds (Wheatley 1995). Archaeologists have combined many of these different methods to achieve more accurate viewsheds (e.g., Llobera 2007). A particularly relevant example of such a combined approach is the study of visual control through inter-visibility of Iron Age hillforts in Catalunya (Ruestes Bitrià 2008).

Llobera (2007) rightly states, however, that introducing any type of variability imposes limitations on our interpretations and that it becomes crucial to define clearly what we can actually say with our particular combination of data and method. It is therefore necessary first to define how visibility will be approached and interpreted in this study, after which a method will be discussed that fits within this approach. Wheatley and Gillings (2000, p. 3) defined the term visibility as "past cognitive/perceptual acts that served to not only inform, structure and organise the location and form of cultural features, but also to choreograph practice within and 
around them." Llobera $(2003,2007)$ similarly emphasizes the role of visibility patterns in structuring space through the intentional positioning of physical features in the landscape. It is up to the archaeologist to decipher how this structuring was achieved in order to identify exactly which patterns were intentionally created, and most importantly to try to understand the role these visual patterns played in the past.

In this study we assume that the presence as well as the absence of a line of sight from one site to another reflects the possibility that (i) this was intentional, (ii) it structured the surrounding space, and (iii) that the way in which it structured space might reveal aspects of the roles ascribed to the line of sight in the past.

\section{Data: topography, sites, chronology, and attributes}

\subsection{Digital Elevation Model}

The digital elevation model (DEM) was created from two sources: points and contour lines (source: ICA, Junta de Andalucía; contour interval 10m). The point heights are unevenly distributed over the landscape, with a higher density of observation in the mountainous Sierra Morena and the foothills of the Sistema SubBético, as well as the more densely urbanized area around modern Seville, and a lower density in the low-lying Guadalquivir valley. The DEM was interpolated with the 'Topo to Raster' tool in ArcGIS 9.3, which was selected because it recreates a more correct representation of ridges from input point and contour data, features that have a significant impact on the results of visibility analyses (Wheatley and Gillings 2000, p. 10). This interpolation technique is specifically designed for creating hydrologically correct DEMs, drawing on both the points and contour datasets (the point heights were selected as the dominant source in the tool). A resolution of $35 \mathrm{~m}$ was chosen for the resulting DEM and it has a root mean square error (RMSE) of $3.37 \mathrm{~m}$ (reflecting the degree of inexactness of the interpolation method used).

\subsection{Settlement data}

A dataset of 190 sites assembled by the 'Urban Connectivity in Iron Age and Roman Southern Spain' project is considered in this study (see Appendix A). The amount and reliability of information available for each site differs greatly due to a variable research history. All 190 sites are settlements of some kind, including major Iberian settlement sites and rural settlements, Roman urban settlements and semi- 
urban/semi-rural agglomerations: it excludes villas and other kinds of rural settlement. Since the reliability of settlement type identification varies we do not distinguish between types of settlement in the formal analysis, although these will be taken into account when interpreting the results. We believe this dataset to be representative of the Roman period towns and agglomerations as well as the larger Iberian settlements. Our knowledge of Iberian rural settlement is less complete; this will be taken into account when interpreting the results. For the majority of sites little is known other than their location and broad periods of occupation. For a further 253 sites no reliable dating information was available, and for most of these identification as past settlements is highly uncertain; these possible sites were not included in this analysis. The dataset reflects our total available knowledge of Iron Age II and Roman settlements in the study area up to the end of the project in 2005 . We believe this represents a settlement pattern that allows us to draw meaningful conclusions with the approach presented here. Although subsequent discoveries can certainly be expected, in particular of Iberian rural settlements, we believe they will not substantially change the conclusions drawn. The dataset was assembled primarily from the following sources:

- Archival: sites listed in regional sites and monuments catalogues held by the Delegacion Provincial de Cultura de la Junta de Andalucía (specifically the ARQUEOS and its later replacement the SIPHA). These draw upon information recorded by archaeologists in the $20^{\text {th }} \mathrm{c}$, as well as works published earlier. The work of Ponsich (1974, 1979, 1987, 1991) form a fundamental part of this, particularly for the Roman settlements.

- Administrative: these are specifically surveys of Iberian and Roman sites undertaken for administrative reasons by the Delegación Provincial de Cultra as part of the Junta de Andalucía's ongoing strategy of updating its regional sites and monuments registers.

- Research: these are sites that were found, investigated or excavated in the course of research projects undertaken by archaeologists based at the Universidad de Sevilla or elsewhere.

- Accidental: sites found or investigated as a result of rescue work ('urgencias') undertaken by archaeologists on behalf of the Junta de Andalucía, whether by excavation or survey. 
- Project: sites visited in the course of the Urban connectivity project for the purposes of checking location and analysis of surface materials for indications of chronology.

\subsection{Chronology}

The sites included in this analysis were all occupied for differing lengths of time within the period of the ten centuries this study is concerned with: from the early fifth century BC until the late fifth century AD. Dates of individual sites were derived from excavation and survey reports as well as from their archaeological record. The accuracy of these sites' chronologies therefore varies enormously. In order to explore long-term change it was decided to use five time-slices according to which sites were grouped together for analysis (see Appendix A):

- Iberian (Iron Age II): early 5th c. BC to late 3 rd c. BC

- Roman Republican: late 3 rd c. BC to late 1 st c. BC

- Early Imperial: late 1 st c. BC to early 3 rd c. AD

- Middle Imperial: early 3 rd c. AD to early 4 th $\mathrm{c} . \mathrm{AD}$

- Late Imperial: early 4 th $\mathrm{c} . \mathrm{AD}$ to late 5 th c. $\mathrm{AD}$

The transition periods used for these time-slices refer to periods of change that are defined by the chronology of different classes of ceramics that are commonly found in the area; the late $3^{\text {rd }} \mathrm{c}$. BC is marked by the first Roman settlements (viz. Italica) and the appearance of imported Italic Black Gloss pottery and subsequently imported Dressel 1 and other varieties of Italic wine amphora; the late $1^{\text {st }} \mathrm{c}$. BC marks the disappearance of the earlier kinds of pottery and the appearance of Terra Sigillata Italica and a range of other kinds of well defined locally produced and imported pottery, such as Terra Sigillata Clara A; the early $3^{\text {rd }}$ c. AD coincides with the appearance of a distinctive class of imported north African pottery, Terra Sigillata Clara $\mathrm{C}$; the early $4^{\text {th }} \mathrm{c}$. AD onwards is represented by the appearance of yet another distinctive class of imported north African pottery, Terra Sigillata Clara D and other imported material. Sadly the coarse chronologies of the vast majority of sites (often defined with an accuracy of a century, especially for those sites known exclusively through survey and surface scatters) do not allow for a much more precise overall periodization. However, it was felt that this archaeologically defined periodization conformed much more closely to the archaeological veracity of these sites, and that was therefore more appropriate than imposing historically defined periods. Although 
this is a convenient approach for exploring long-term changes of patterning in a large dataset using formal methods, it is necessarily coarse and even enforces the traditional chronological boundaries this paper seeks to challenge. A more fuzzy or probabilistic approach to dealing with temporal uncertainty should be preferred (e.g., Crema et al. 2010) but lies outside the scope of this paper. Still, earlier in the project fuzzy dates were employed as a means to integrate data from various sources, and in particular to record perceived bias in use of terminology (Earl and Keay 2007). We believe the current approach will still allow for the observation of large-scale long-term change that is the aim of this case study, although with a low degree of chronological accuracy.

\subsection{Site attributes}

In this case study we will evaluate the role of three attributes in giving rise to the observed inter-urban connections: urban status, prominent elevated locations, and location on road or river networks. In addition to these three we will consider the potential Iberian origins of sites as an attribute to evaluate interactions between Iberian sites that continue in occupation. Lists of sites for each of these attributes are included in Appendix A.

Urban status: as mentioned above, many sites in the study area were attributed an urban status by Rome in the Early Imperial period. Thus, epigraphic and historical sources indicate that Hispalis (Seville), Astigi (Écija) and Urso (Osuna) were established as coloniae under Caesar and Augustus, while many others gained the status of municipium in the course of the $1^{\text {st }} \mathrm{c} \mathrm{AD}$, particularly after the later $1^{\text {st }} \mathrm{c} \mathrm{AD}$ (Keay 1998b, p. 85). The acquisition of the legal privileges implicit in these statuses is a good measure of the political integration of these communities into the Roman Empire and, therefore, can be read as a regional expression of politically-based urban hierarchies. However, there are many difficulties surrounding the identification of an archaeological site with a town mentioned in ancient written sources, an issue that is particularly acute for the many possible municipia in the region. Here we decided to follow the list of coloniae and municipia compiled by Simon Keay (1998b, Appendix II) as a prime reference. This list was itself compiled from a range of secondary sources (Fear 1996; Knapp 1983; Sillières 1991; Stylow pers. comm.; Tovar 1974).

Prominent elevated locations: a qualitative assessment of prominent locations is included as a site attribute in this analysis to evaluate the effect of the DEM (which 
provides a quantitative assessment of prominent locations). Project members visited all of the sites in the study area in the framework of the 'Urban Connectivity in Iron Age and Roman Southern Spain' Project. They described the physical location of sites using a range of qualitative categories. Sites that were described with the following attributes were considered to have a prominent elevated location: hill, low hill, plateau, plateau side.

Road and river networks: this attribute represents sites located on the main transport routes in the study area: the Via Augusta, the Guadalquivir river, and the Genil river. Transhumance routes were not taken into account because their exact course and dating is often unknown. The course of the Via Augusta in this area is well known and has been thoroughly studied (Sillières 1991; Corzo and Toscano 1992). In antiquity the Guadalquivir and Genil rivers were navigable up to Córdoba (Corduba) and Écija (Astigi) respectively (Strabo 3.2.3; Ponsich 1991, Fig. 6). All sites along these rivers up to these points were considered to be part of the river network. It is notable that almost all towns along these transport routes were either coloniae or municipia and for most of them we know the ancient name (see Appendix A for a full list).

\section{Method: an approach for exploring changing visibility networks}

To address this study's research questions we developed an approach that allows us to explore the structure of visibility networks as well as evaluate our assumptions about the factors driving the emergence of these changing structures. Our combined method consists of a few steps that will be introduced here: generating probable viewsheds, creating visibility networks, exploring network structure, and creating statistical models of emerging networks (with ERGMs).

\subsection{Probable viewsheds}

As mentioned above, in formal visibility studies a measure of variability is often added to address methodological and theoretical shortcomings of the approach. In this study we will add variability in two ways: through probable viewsheds and by analyzing the results in different bands of distance. A probable viewshed uses a Monte Carlo simulation approach to identify the probability that a location is visible to an observer from a specific viewing point. The probable viewshed was first developed by Fisher $(1992,1995)$ to compensate for the imperfections in the DEM 
and the variability between algorithms used to create viewsheds. As such the error introduced in a probable viewshed reflects the RMSE of the DEM. In this study we use a $5 \mathrm{~m}$ error, which is slightly higher than the RMSE of $3.37 \mathrm{~m}$ and enhances the effect of decreasing probability of visibility with distance away from the observer. The probable viewshed was iterated 100 times for each of the 190 sites and the observer height was fixed at $1.7 \mathrm{~m}$. An elevated target height was considered uncritical since for many sites we have no knowledge of the architecture and a target height of $1.7 \mathrm{~m}$ was discarded since inter-visibility between observers was not the aim of the analysis. It was decided to consistently use a target height of 0m (Fig. 5).

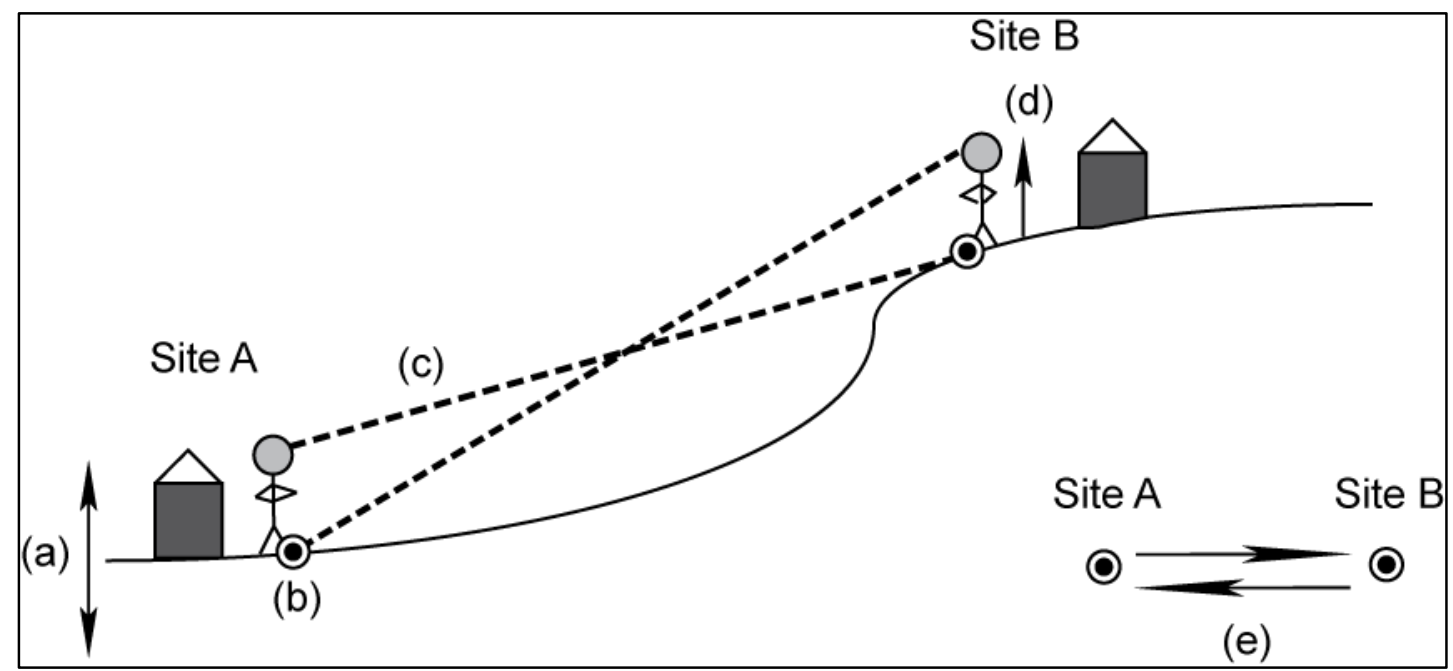

Fig.5. (a) maximum random error in probable viewshed $=5 \mathrm{~m}$; (b) observer point site $A$ and target point for observer site B; (c) line-of-sight with probability $p_{a}$ from observer A to target point site B; (d) observer height $=1.7 \mathrm{~m}$; (e) inter-visibility network where site A is connected to site B with probability $p_{a}$ and site B is connected to site A with probability $p_{b}$.

\subsection{Observation point locations}

A single observer point was created for each of the 190 sites in the analysis. In general the observer point was either positioned on the site location or at the center of the site area (if the area is known, which is not the case for the vast majority of sites). Observer points were positioned on prominent features when known (for example the Roman gate at Carmona, see below). These point locations are more dense in the campiña and around the Genil river, areas that have traditionally always been more densely occupied (Ponsich 1991), and they are less dense around the Guadalquivir, the Sierra Morena, and the lacus ligustinus (Fig. 1). This distribution has a significant impact on the results of this study, as revealed through a cumulative viewshed analysis (not presented here, see Brughmans 2014), and it will be taken into account when interpreting the results. The cumulative viewsheds also reveal a gradual 
decrease over time of overall visibility in the study area, the increase over time of the visual prominence of one area (northwest of Osuna), the to-be-expected consistent visual prominence of sites located on elevations, and the consistently low degree of visibility of the major roads and rivers.

However, past urban settlements were not just point locations but extended over sometimes considerable areas. One could argue that inter-visibility should therefore be derived from multiple observer points per settlement. However, for $23 \%$ of sites in this study the extent is unknown and for most of the others the minimum area is an estimate for which the exact geographical extent is unknown (Fig. 6; see also the rank-size analysis in Keay 1998b, Fig. 4). Deciding where the multiple observer points per site should be located therefore becomes impossible for most sites. We decided to remain consistent and only select a single observation point per site, even though this involves a significant limitation on the area visible from each site. At an earlier stage of the project some preliminary analyses were undertaken assigning ten viewer locations at random within the site polygons. However, the considerable uncertainty regarding the accuracy of these polygons, and in particular their sensitivity to period of analysis, meant that this was not explored further. A detailed study of the past occupied area of each site was not possible for this study and should form the focus of future work, allowing for re-analysis of inter-visibility with multiple viewer points.

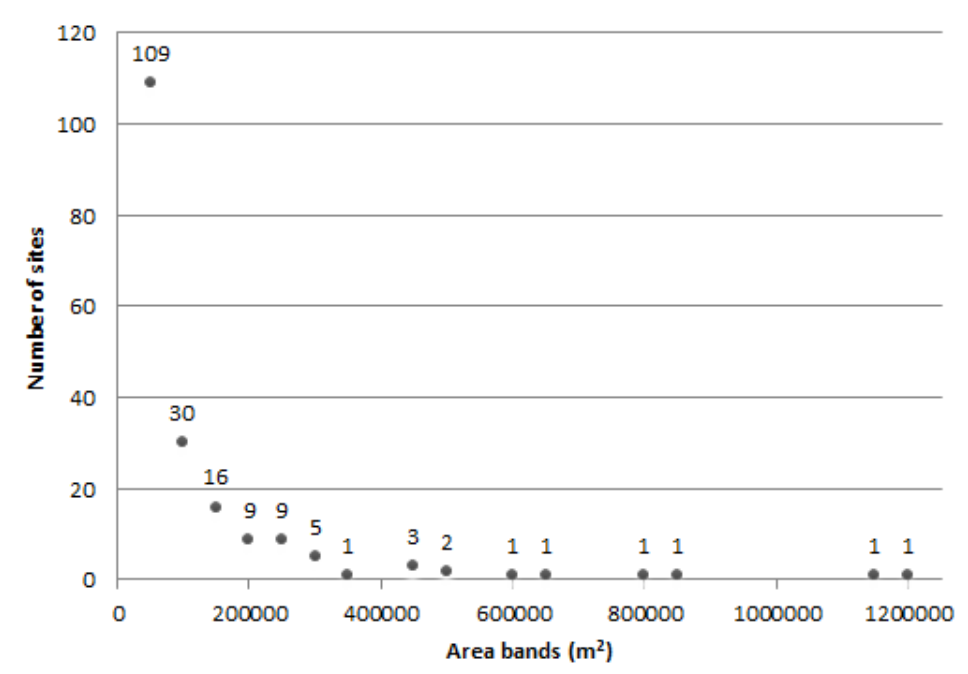

Fig. 6. Frequency distribution of the number of sites per area band of 50,000 $\mathrm{m}^{2}$. All areas are minimum estimates. Of the 109 sites in the lowest band 43 sites have an area that is unknown or lower than 1,000 $\mathrm{m}^{2}$. 


\subsection{Visibility network creation}

From the probable viewsheds of all 190 sites a visibility network is created in which nodes represent sites (the observer point locations) and the arcs represent the presence of a line-of-sight from a site to another site. These arcs have a probability attributed to them derived from the number of times out of 100 that the cell in site A's probable viewshed on which the observer point of site B is located is visible. This results in a directed network in which lines of sight from and to sites can be distinguished, and where all sites have a differing probability of being visible from every other site (Fig. 5). The network can subsequently be explored per period by only including those sites occupied during a certain period. We will also explore the differences between network patterns with high probability arcs and those with low probabilities. Finally, we decided to focus our analysis on lines of sight at a distance of up to $20 \mathrm{~km}$, because at such distances large architectural features, and presumably communication signals, are still visible. However, in our discussion of the results we will also make reference to some patterns of interest over distances greater than $20 \mathrm{~km}$, since observations in the study area confirm that long-distance inter-visibility of sites is not impossible (Keay and Earl 2011). The inter-visibility of Carmona in the vega and Castillo de Mulva in the foothills of the Sierra Morena over a distance of ca. $30 \mathrm{~km}$ is a clear example of this.

The coarseness of the DEM and the use of a single observer point per site might shed doubt on the use of directed networks. However, we believe their use is justified in this study for two reasons. Firstly, the probabilistic viewshed method gives rise to sometimes strong differences in the probability of lines of sight between pairs of sites: $31.6 \%$ of node-pairs have a difference in the probability of the arcs between them of more than $10 \%$; whilst $4.7 \%$ of node-pairs have a difference in the probability of the arcs between them of more than 50\%. These differences have a strong impact on the number of reciprocal ties and the network patterns when the networks are explored using thresholds on different probability values. Secondly, the archaeological hypotheses we aim to test require an abstraction and representation as directed networks (e.g. visual control or visual prominence). 


\subsection{Exploratory Network Analysis}

The resulting networks are static and are not suitable to explore issues of movement through the landscape. Instead, this study will focus on how patterns of inter-visibility between sites change over time, how these patterns emerged, and how these might have structured interactions between urban settlements. This can in part be done by exploring these static networks using exploratory network measures.

The local node-based measures used include indegree, outdegree, and clustering coefficient. The global network-based measures include number of nodes, number of arcs, clustering coefficient, number of connected components, average degree, diameter, average shortest path length, and density (for definitions see the glossary in the introduction to this special issue (Collar et al. 2015)). The indegree of site $\mathrm{A}$ is the number of sites from which site A can be seen. The outdegree of site A is the number of sites that can be seen from site A. The diameter of a network is the longest path between a pair of nodes; if a network is disconnected the diameter of the largest connected component is given. The density is the observed number of visibility links between all sites divided by the total number of possible links between them. The clustering coefficient of site $\mathrm{A}$ is the observed number of visibility links between the direct neighbours of A divided by the total number of possible links between these.

\subsection{Exponential Random Graph Models}

Exponential Random Graph Modelling is a statistical simulation approach that compares the structure of simulated networks which represent a researcher's hypothesis of how a certain observed network emerged, with the known structure of this observed network. For a detailed ERGM reference work, see Lusher et al. (2013). For a more technical description of this type of models applied to archaeological visibility networks see Brughmans et al. (2014).

Social network analysts often use an archaeological analogy to explain the concept of an ERGM (e.g., Lusher and Robins 2013, p. 18). Past material remains are like 'snapshots' of dynamic processes in the past: static, fragmentary cross-sections of a social process taken at a given moment. Archaeologists explore the structure of these material residues to understand past dynamic processes. If one were to observe multiple cross-sections in sequence, changes in the structure of these fragmentary 
snapshots would become clear. This is exactly what an ERGM aims to do: to explore hypothetical processes that could give rise to observed network structure through the dynamic emergence of small network fragments or subnetworks (called configurations, e.g. Figs. 3-4). These configurations can be considered the building blocks of networks; indeed, $\mathrm{LEGO}^{\mathrm{TM}}$ blocks offer a good analogy for explaining ERGMs. To give an example, a network's topology can be compared to a LEGO $^{\mathrm{TM}}$ castle boxed set, where a list of particular building blocks can be used to re-assemble a castle. But a LEGO $^{\mathrm{TM}}$ castle boxed set does not assemble itself through a random process. Instead, a step by step guide needs to be followed, detailing how each block should be placed on top of the other in what order. By doing this we make certain assumptions about building blocks and their relationship to each other. We assume that in order to achieve structural integrity in our LEGO ${ }^{\mathrm{TM}}$ castle, a certain configuration of blocks needs to appear, and in order to make it look like a castle other configurations will preferentially appear creating ramparts, turrets, etc. ERGMs are similar: they are models that represent our assumptions of how certain network configurations affect each other, of how the presence of some ties will bring about the creation or the demise of others. This is where the real strength of ERGMs lies: the formulation and testing of assumptions about what a connection between a pair of nodes means and how it affects the evolution of the network, explicitly addressing the dynamic nature of our archaeological assumptions.

More formally, exponential random graph models are a family of statistical models originally developed for social networks (Anderson et al. 1999; Wasserman and Pattison 1996) that aim to scrutinize the dependence assumptions underpinning hypotheses of network formation by comparing the frequency of particular configurations in observed networks with their frequency in stochastic models.

The hypotheses introduced in section 2.3 above represent different assumptions archaeologists make about certain network patterns (for example, in order for a communication link to exist and function between two settlements they need to be inter-visible). These theoretical assumptions can be represented using network configurations (Figs. 3-4). In order to test hypotheses of the emergence of networks one can create an ERGM that includes configurations representing assumptions that are fundamental to the tested hypothesis. The model then generates a large number of networks whose structure will reflect the configurations included in the model. The simulated outcomes of the ERGMs are then compared with the 
observed structure of the inter-visibility network under study, allowing one to further discuss the likeliness of the hypotheses. For example, if the model which represents our hypothesis cannot give rise to networks with a similar structure as the observed network, then this hypothesis might be considered less probable than modelled hypotheses which do give rise to a similar network structure as the observed network.

\subsection{Software}

The probable viewsheds were created in ArcGIS 10.1 using a python script written by David Wheatley (University of Southampton). Networks were created using UCINET, PAJEK and CYTOSCAPE. Exploratory network measures were derived with PAJEK. ERGMs were estimated and fitted using PNET.

\section{Results of the combined approach}

\subsection{Exploratory network analysis ${ }^{1}$}

\section{Sensitivity analysis of exploratory network metrics}

In the following exploratory network analysis and the ERGMs we will largely focus on lines of sight with a probability over $50 \%$. However, the results of network measures can vary significantly when a network is reduced to subnetworks using certain thresholds (e.g., Peeples and Roberts 2013). We performed a sensitivity analysis to explore the effects of different thresholds on the probability of arcs on the overall results of the network measures and the site rankings. This analysis was performed for the Early Imperial network only, although similar results can be expected for networks of other periods given their general structural similarity. The networks used are directed, contain isolated nodes, and do not contain loops (arcs from one node to itself).

The results suggest that for many measures (global density, all degree centralization, local clustering coefficient) the networks with probability $>50 \%$ give stable results, indicating that a focus on these high-probability subnetworks in the exploratory analysis is representative (Fig. 7). However, the exploratory network analysis should also incorporate the global clustering coefficient, and the indegree and

\footnotetext{
${ }^{1}$ Appendix B presents the results of the local exploratory network measures.
} 
outdegree rankings of low probability networks, since these show significant sensitivity to changing thresholds.

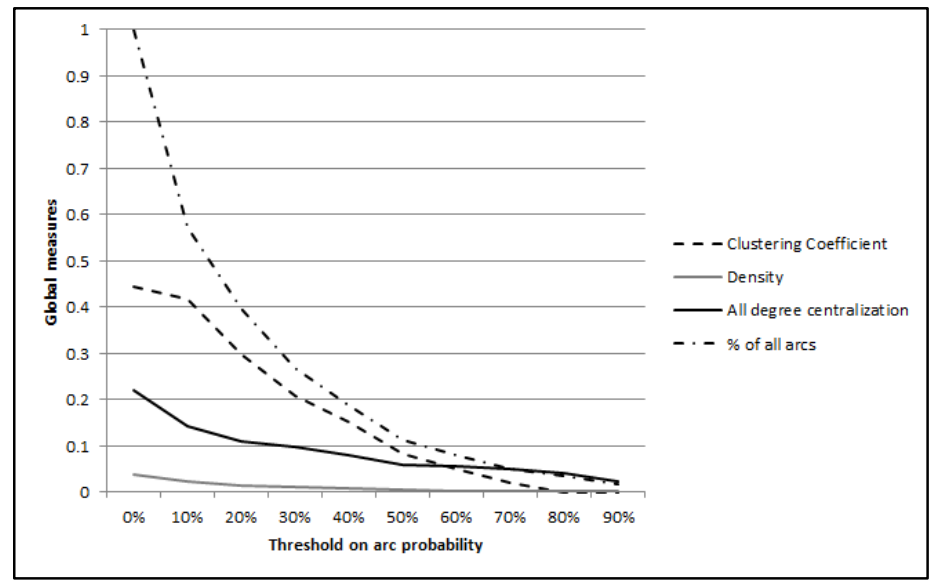

Fig. 7. Results of global network measures for ten networks with a different minimum probability of arcs (in \%).

\section{Global network measures ${ }^{2}$}

The global network measures in table 2 confirm that the number of nodes and arcs decrease significantly through time. To some extent this can be explained through the general decrease in the number of occupied settlements (see Table 1 above). However, in this exploratory network analysis we will try to address the extent to which the network patterns cannot be explained simply with reference to a decrease in the number of sites. The number of sites and lines of sight per period are nevertheless important since they determine the minimum and maximum values of many network measures, and they are therefore always used as a benchmark for interpreting the analytical results and comparing across periods.

The networks limited to a $20 \mathrm{~km}$ radius of all periods are very fragmented and sparse (Table 2). The number of visibility links per site remains low throughout all periods, although there is a slight increase in the normalized average degree. The normalized number of connected components and the density show a similar slight increase, indicating an increasing fragmentation through time while the largest components become denser.

\footnotetext{
${ }^{2}$ The results presented in this section only take into account pairs of nodes that are connected and do not include the many isolated nodes dated to these periods (see Fig. 11). This affects the normalized and averaged results as well as the density and clustering coefficient (note that network density including isolates is also included in the tables). This decision was made to enhance the differences between these measures and to focus this first step of the analysis explicitly on the lines of sight that are present. Isolates are included in the local exploratory network analsysis and the ERGMs.
} 
It is notable that the percentage of highly probable arcs $(>50 \%)$ generally decreases through time, with the Iberian and Republican periods showing a significantly higher proportion of high-probability lines of sight than the Imperial periods (Fig. 8). A more nuanced picture emerges when we compare lines of sight of different lengths. The drop in the proportion of high probability lines of sight in the Early Imperial period shown in figure 8 is the result of a decrease of high-probability arcs longer than $50 \mathrm{~km}$. When we take arcs of all probabilities (1-100\%) into account we see that the proportion of shorter-distance arcs increases through time, while the proportion of arcs with lengths between 20 and 50km decreases (Fig. 9). The graph in figure 10 with the number of high probability arcs is quite different, however. A significantly higher proportion of arcs in the Iberian and Republican periods have a length larger than $50 \mathrm{~km}$, indicating that a considerable proportion of the shorter distance links in these periods have a low probability. Moreover, the majority of arcs with high probability in the Iberian period fall within the 20 to $50 \mathrm{~km}$ range. Although this proportion does not change very much, the subsequent periods do show an increase in the proportion of arcs shorter than $20 \mathrm{~km}$ at the expense of arcs larger than $50 \mathrm{~km}$. The low probability arcs show a similar trend towards an increasing proportion of short distance lines of sight. All this indicates that long-distance lines of sight become extremely rare in the Imperial periods. This might be considered a result of the decrease in the number of settlements on elevations. The lines of sight shorter than $20 \mathrm{~km}$ on the other hand become more prominent in the Imperial periods.

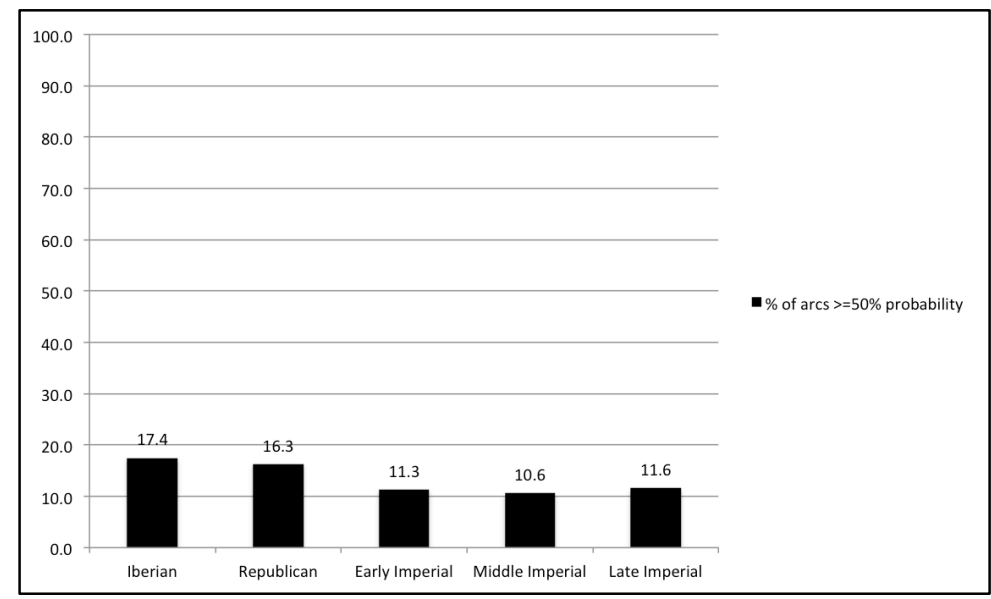

Fig. 8. Percentage of arcs per period with a probability higher than or equal to $50 \%$. 


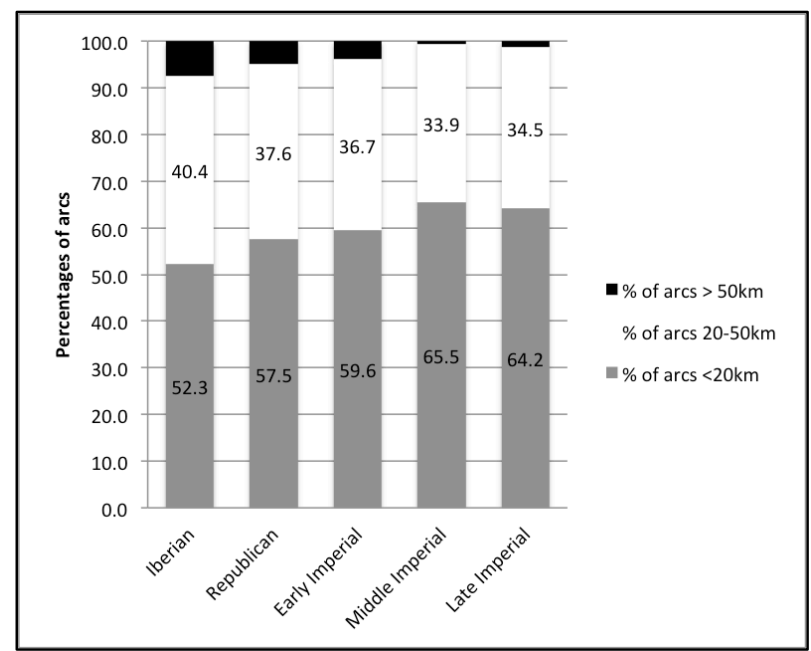

Fig. 9. Percentages of arcs shorter than $20 \mathrm{~km}$ and $50 \mathrm{~km}$ and longer than $50 \mathrm{~km}$ for each period. All arcs with probabilities between 1 and $100 \%$ were included in this graph.

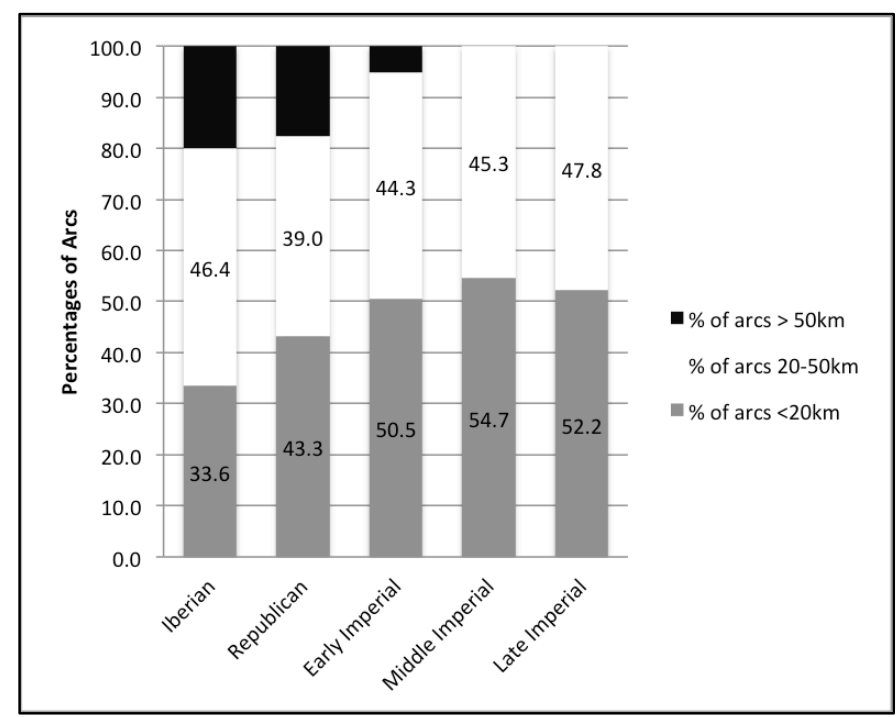

Fig. 10. Percentages of arcs shorter than $20 \mathrm{~km}$ and $50 \mathrm{~km}$ and longer than $50 \mathrm{~km}$ for each period. Only arcs with probabilities over $50 \%$ were included in this graph.

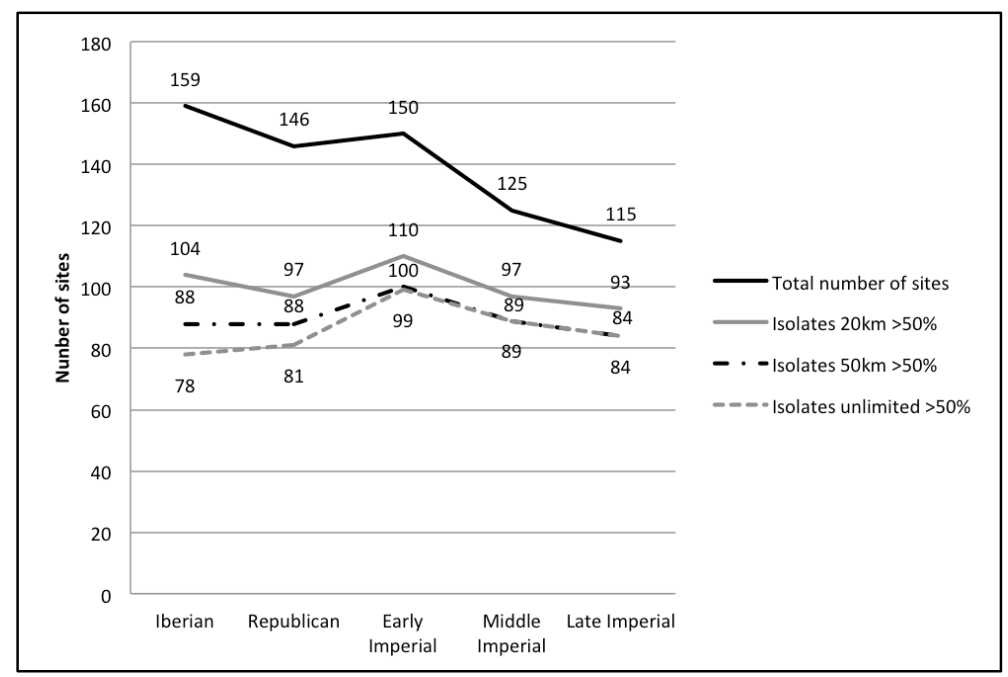

Fig. 11. Total number of sites and number of unconnected nodes per period and network type. 
Table 2: global measures networks limited to $20 \mathrm{~km}$ radius with probability $>50 \%$.

\begin{tabular}{rccccc}
\hline & Iberian & Republican & Early Imperial & Middle Imperial & Late Imperial \\
\hline Clustering coefficient & 0.107 & 0.108 & 0.056 & 0.000 & 0.000 \\
Connected components & 13 & 12 & 11 & 9 & 8 \\
Con. Comp. normalised & 0.241 & 0.245 & 0.282 & 0.321 & 0.364 \\
Diameter & 5 & 6 & 4 & 4 & 4 \\
Node pairs & 204 & 181 & 98 & 51 & 40 \\
Av. Degree & 1.815 & 1.837 & 1.694 & 1.608 & 1.500 \\
Av. Shortest path length & 1.917 & 2.044 & 0.042 & 1.429 & 1.364 \\
Av. Degree normalised & 0.034 & 0.037 & 39 & 0.051 & 0.062 \\
Dedes & 54 & 49 & 0.033 & 0.038 & 22 \\
Density & 0.028 & 0.030 & 0.0022 & 0.0019 & 0.054 \\
\hline Arcs & 79 & 71 & 49 & 29 & 0.0019 \\
\hline
\end{tabular}

\section{Network analysis of arcs $<20 \mathrm{~km}$}

As mentioned above, these networks of lines of sight up to $20 \mathrm{~km}$ are very fragmentary and the vast majority of nodes are unconnected (Table 2, Fig. 12-13). Only a few areas have a higher number of sites that are inter-visible and these areas make up the main components of the networks: the middle- and upper-Genil valley (including the sites of La Alcuza, Mochales, El Mocho, and Castillo de Alhonoz), the area around Pancorvo (including the sites of Pancorvo, Cerro del Bollo, Las Aguzaderas, and Las Mazmorras), and the middle Corbones valley (including the sites of San Pedro I, La Torre II, and Porcún I). The latter cluster disappears in the Middle Imperial period when these sites cease to be occupied. As one would expect, the sites within the denser components have higher clustering coefficients and a higher indegree and outdegree.

The networks including arcs of lower probability show the same core areas (Fig. 13). What the networks of higher probability do not show, however, are the two clusters of low probability inter-visibility along the lower Guadalquivir valley (the area of Santiponce and Seville) and the lower Genil valley. The former emerges in the Republican period and is no longer present in the Late Imperial period, while the latter is a fully connected cluster present in all periods (the connected cluster includes Doña Mencia, Cortijo Nuevo, La Saetilla, Las Valbuenas, Isla del Castillo, and Las Animas).

There are more sites with exclusively incoming arcs of high probability and no outgoing arcs (i.e. sites from which no other sites can be seen but that are visible from other sites) than the other way around. An example of this in the Iberian and Republican periods is Pozo del Carretero, a hilltop site located in the densely urbanized middle Corbones valley. Morón de la Frontera serves as an example for the 
Early and Middle Imperial periods (although this site was occupied throughout the other periods as well, when it was not visible over short distances from other sites). Morón de la Frontera is located on a hilltop in an area with a low density of sites. An exception to this trend is Tejada la Vieja in the Iberian period, which cannot be seen but from which two sites can be seen. The latter occupies a prominent fortified location on a plateau in the foothills of the Sierra Morena on the western extent of the study area, but given the low density of sites in this part of the study area the site does not occupy as prominent a position on the networks as its location would suggest. The ERGMs discussed below suggest that these types of configurations are indeed quite key to understanding these networks' structure.

The sites with a Roman urban status are not very prominent in these $20 \mathrm{~km}$ networks. The coloniae of Seville, Écija, and Osuna are not inter-visible with any other sites with high probability, and low probability arcs connected to these sites are few as well. Seville can be seen from Piesolo I with 1\% probability, Écija can be seen from La Alcuza with 29\% probability, and Osuna can be seen from Cerro del Calvario with $10 \%$ probability. Very few of the municipia have high probability inter-visibility links: Las Cabezas de San Juan and Palmilla I are inter-visible (84\% probability), Pancorvo can be seen from the municipium of Torre del Aguila (66\%), the riverside municipia of Cantillana and Alcolea del Rio are inter-visible (100-96\%), and Mesa del Almendro can be seen from the municipium Peñaflor (56\%). Many of the municipia do have low probability inter-visibility links, however, including El Casar, El Gandul, Torre del Aguila, Torres de Alocaz, Lebrija, Castillo de la Monclova, Isla del Castillo, Alcala del Rio, Santiponce, Gerena, and San Juan de Aznalfarache. Carmona does not have any lines of sight to close-by sites.

We can conclude that these networks limited to a $20 \mathrm{~km}$ radius around settlements represent local patterns of inter-visibility and are sensitive to the distribution of sites. All key clusters identified in these networks are areas with a high density of sites. Many visually prominent sites that have a key position in the networks are occupied in the Iberian and Republican periods but cease to be so in the Imperial periods (e.g., Pancorvo, Tejada la Vieja, Tablada, San Pedro II, Pozo del Carretero).

Although we consider lines of sight longer than $20 \mathrm{~km}$ of minor importance for enabling communication and control, a few striking patterns of the lines of sight with a length between 20 and $50 \mathrm{~km}$ should be mentioned. These lines create links between 
areas of dense local inter-visibility, and a number of sites (e.g., Morón de la Frontera) can only be considered visually prominent at these longer distances. As the number of occupied sites decreases through time, however, so does the degree of local clustering, the indegree and outdegree. The longer distance networks therefore confirm the trend evidenced by the shorter distance networks: the networks increasingly fragment and with a few exceptions (e.g., Morón de la Frontera) the proportion of local visibility ties becomes increasingly dominant. Few sites with an urban status are inter-visible with high probability over such long distances. The colonia Osuna is connected to Cagancha with 57\% probability. Few municipia have arcs of high probability. Noteworthy are the strong inter-visibility links between Carmona and Cantillana, and Cantillana and Alcolea del Rio. El Casar is inter-visible with Palmilla I and Dehesa de las Majadilas.

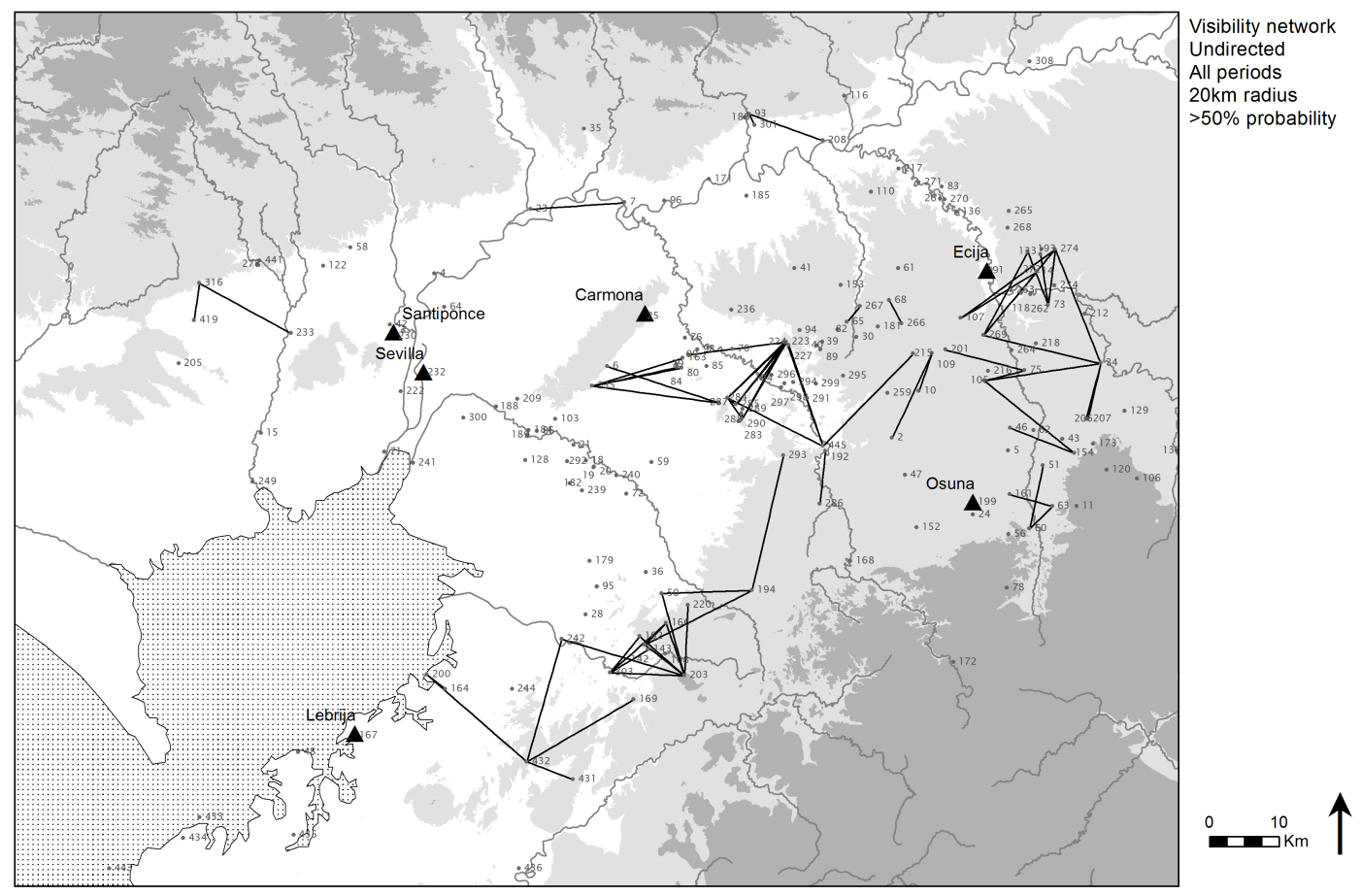

Fig. 12. Undirected visibility network for all periods combined limited to a $20 \mathrm{~km}$ radius around observers and ties $>50 \%$ probability. 


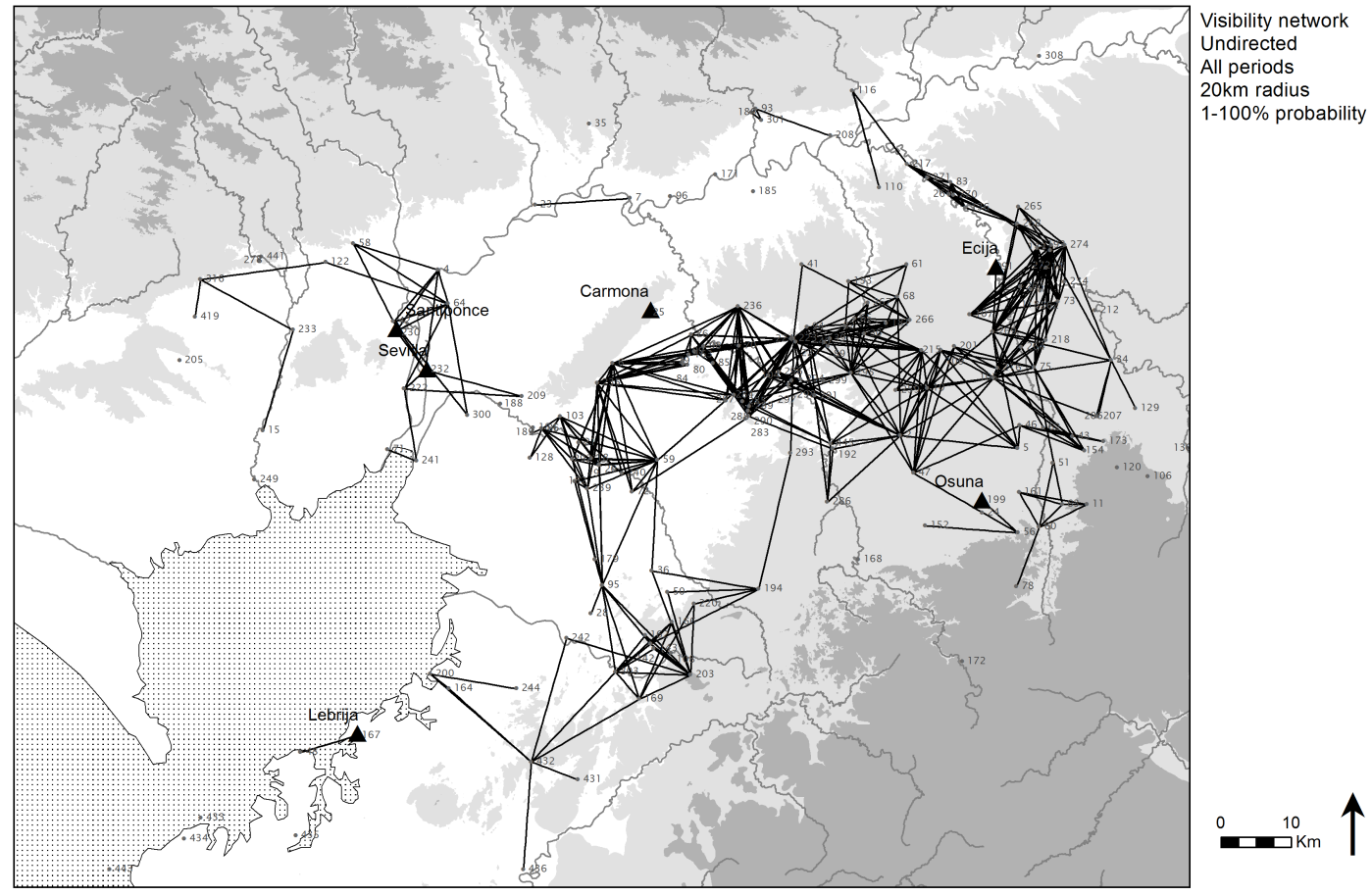

Fig. 13. Undirected visibility network for all periods combined limited to a $20 \mathrm{~km}$ radius around observers and ties $>0 \%$ probability.

\subsection{Exponential Random Graph Modelling}

This section will explore what kinds of processes were likely or unlikely to have led to the observed visibility networks. The assumptions that go into these models are introduced from the bottom-up, starting with random processes, followed by simple models focusing just on the emergence of network structural features, and finally models that include site attributes. Each of these assumptions represents different hypotheses, as discussed in section 2.3. Unlike for the global exploratory network analysis, isolates were included in the ERGMs since the tendency for sites to be visually isolated is of interest in this study. All models discussed here only take arcs with a probability $>50 \%$ into account. Estimate and goodness of fit results are available in appendix $\mathrm{C}$.

\section{Bernoulli random graph models}

In the first instance models with only one dependence assumptions, the probability of arc creation, were formulated for networks of each period limited to 
$20 \mathrm{~km}$ arcs. For each model 50 million networks were simulated ${ }^{3}$ from which 1000 samples were selected. ${ }^{4}$ The frequency of each configuration was counted for the 1000 sample networks of each model (see Appendix C tables C1-C5) and were compared with the configuration counts obtained from the observed networks in a goodness of fit test.

Table 3 shows that none of the Bernoulli random graph models manage to produce networks which are structurally similar to the observed networks. This indicates that these observed networks are significantly different from randomly generated networks with the same directed density. These results suggest that nonrandom processes gave rise to the observed visibility networks. Although this conclusion might sound obvious, it is by no means trivial. The processes of site selection that give rise to these visibility patterns are governed by a complex mix of social decisions that can hardly be considered random. Yet our information about these decisions (in this case represented by the observed networks) is fragmentary and might therefore appear to us to have been the result of random processes. In such cases we cannot suggest processes other than seemingly random processes that are more likely to have given rise to these networks, since the information available to us does not allow validation of such alternative processes. It is worth pointing out, however, that the Middle and Late Imperial Bernoulli random graph models manage to reproduce a number of structural features of the observed networks for these periods. Indeed, as we shall argue below, the ERGM method suggests that the data for these periods might not allow us to draw many conclusions about the emergence of these networks.

Having established that for all observed networks random processes do not provide a good solution, we can start to formulate new models suggesting alternative processes that might turn out to be more likely to have happened in the past.

Table 3. Proportion of configurations of the simulated networks which show a good fit with the observed networks (networks limited to a $20 \mathrm{~km}$ and $50 \mathrm{~km}$ radius for each period, no attributes).

\footnotetext{
${ }^{3}$ By using the directed density results of the observed networks it was ensured that all randomly simulated networks have the same directed density, and therefore the same number of nodes and arcs, as the observed networks (although small variations in the number of arcs were allowed due to rounding the density score to four decimal places).

${ }^{4}$ The number of simulations was taken as high as 50 million to have a higher diversity in the distribution of results, which led in most cases to better fits than when only 1 million simulations were performed. However, the number of samples taken from these simulations (and on the basis of which the significance tests were performed) was not increased beyond the default 1000 to avoid enforcing significant results.
} 
1000 samples were taken from 50 million randomly generated networks. None of the Bernoulli random graph models succeed in reproducing the structure of the observed networks, although those for the Middle and Late Imperial periods manage to reproduce some structural features.

\begin{tabular}{rccccc}
\hline 20km networks & Iberian & Republican & $\begin{array}{c}\text { Early } \\
\text { Imperial }\end{array}$ & $\begin{array}{c}\text { Middle } \\
\text { Imperial }\end{array}$ & $\begin{array}{c}\text { Late } \\
\text { Imperial }\end{array}$ \\
\hline \hline $\begin{array}{r}\text { Proportion configurations } \\
\text { with good fit }\end{array}$ & $0 / 52$ & $0 / 52$ & $0 / 52$ & $26 / 52$ & $21 / 52$ \\
\hline
\end{tabular}

ERGMs of arcs $<20 \mathrm{~km}$

ERGMs were estimated for the observed network of each period. The ERGMs presented here all show a good fit with the observed networks, but are by no means the only possible ERGMs and should be considered the outcome of a process of trialand-error guided by our theoretical assumptions of what processes gave rise to these networks (for an example of the ERGM creation process see Brughmans et al. 2014). All estimated models and goodness of fit results are presented in Appendix C. When interpreting these results we focus on the significant effects and on whether these have a positive or negative value. A positive value indicates a tendency towards the creation of this type of configuration, while a negative value indicates a tendency against this configuration.

The ERGMs show some similarities throughout all periods (Table 4). Most striking is the significant and positive reciprocity effect of all periods, i.e. we see more inter-visibility than we might expect to emerge purely by chance given the other effects in the model. In the probable viewshed approach used for this case study a high degree of inter-visibility is to be expected, although there are sometimes strong differences in the probability of incoming and outgoing lines of sight (as explained in section 4.3 above). All periods also show a positive alternating-in-star effect, which suggests that the indegree distribution is spread and includes sites with a high number of incoming lines of sight.

However, the similarities seem to end there. In fact, the models suggest that the role of indegree hubs is very different for each period. Indeed, this alternating-instar effect is only significant for Iberian, Republican, and Early Imperial periods, making the indegree hubs a less important structural feature for the later periods. Most interesting is the significant and negative 2-in-star effect for the Republican and Early Imperial periods, which indicates that in these periods the network tends to be dominated by indegree hubs and not sites with a lower indegree. The distribution of outgoing lines of sight on the other hand suggests that only for the Iberian period can 
one argue for a tendency towards the emergence of outdegree hubs with a high degree of visual control: the alternating-out-star is only significant and positive for the Iberian period, while the other periods do not seem to have evidence for processes giving rise to sites with high visual control (for most periods it is in fact negative).

Another difference between the Iberian and later period networks is its significant and negative 2-path effect. This suggests that settlements that are visually prominent tend not to be visually controlling. It also suggests that paths through the network necessary for passing on information through signalling might not have been purposefully established. Moreover, this effect is combined with a positive and significant transitive triad (T9) in the Iberian, Republican and Early Imperial periods. This indicates that if a 2-path occurs it tends to be closed. We believe this process to be a better representation of one leading to clusters of inter-visible settlements around a visually controlling settlement, than of one leading to a communication network.

Finally, one needs to acknowledge the significant and negative isolates effect in the Iberian and Republican periods: sites will tend to have at least one line of sight connected to them. Moreover, the Republican period model has a significant negative source effect and so there are fewer peripheral sites with only one incoming line of sight than one would expect to see purely by chance. This can be partly explained through the higher number of sites and higher site density in this period. The Middle Imperial period on the other hand sees a significant positive isolates effect, which could be explained by the lower site density, but also the lower number of sites located on visually prominent elevations.

Although all of these models have a good fit to the observed networks and succeed in reproducing structural features that are not explicitly modelled (like the path length- and degree distributions), one cannot ignore the low number of significant effects for the Middle and Late Imperial periods. These results seem to reflect the results of the Bernoulli random graph models for these periods, and suggest that the available data might not allow us to deduce more than the most obvious effects (like reciprocity).

Table 4. Final ERGMs for networks limited to $20 \mathrm{~km}$ and with arcs $>50 \%$ probability. For all circuit configurations $\lambda$ was set to 2 . Asterisks indicate significant effects for which absolute value of estimates are more than twice the standard error. A positive value indicates a tendency towards the creation of this type of configuration, while a negative value indicates a tendency against this configuration.

\begin{tabular}{llcccc}
\hline & & & Early & Middle & Late \\
Configurations & Iberian & Republican & Imperial & Imperial & Imperial \\
\hline \hline
\end{tabular}




\begin{tabular}{rllccccccc} 
reciprocity & 8.00 & $*$ & 6.81 & $*$ & 8.69 & $*$ & 6.98 & $*$ & 8.59 \\
2-in-star & & & -3.66 & $*$ & -4.63 & $*$ & -3.30 & $*$ \\
2-out-star & & & 0.15 & & -0.05 & & -0.25 & \\
path2 & -0.52 & $*$ & 0.12 & & 0.90 & & 0.86 & -0.74 \\
T8 & & & & & & & & 0.08 \\
T9 & 0.40 & $*$ & 0.54 & $*$ & 0.58 & $*$ & & \\
Sink & -2.29 & & -1.16 & & & & & \\
Source & -1.28 & & -5.87 & $*$ & & & & \\
Isolates & -3.23 & $*$ & -6.20 & $*$ & -0.74 & & 0.87 & 1.07 \\
AinS & 2.35 & $*$ & 10.02 & $*$ & 5.75 & $*$ & 3.92 & 1.85 \\
AoutS & 2.61 & $*$ & 0.21 & & -0.03 & & -1.07 & 0.56 \\
AinAout-star & & & & & 0.26 & & & -0.33 \\
\hline
\end{tabular}

\section{ERGMs of Early Imperial attributed networks}

The previous sections described models with purely structural effects, addressing the extreme question: "what if lines of sight were the only factor influencing site location." Addressing this question was necessary to be able to explore what processes are suggested by the visibility networks themselves, before adding other explanations to the mix. The current section will add another layer of complexity to the processes suggested by the visibility networks, by exploring to what extent a few features or attributes of sites might have shaped these processes. This can only be tested for the Early Imperial period due to the nature of the attributes (discussed above). We would like to stress again that ERGMs are not designed to take the landscape's topography into account as a constraint in these processes (as explained in section 2.3). This section therefore merely illustrates another way in which ERGMs can be used to explore factors influencing site locations, one that should be complemented in future research with approaches that do take topography into account.

The results of the attributed models are presented in Table 5. They are based on the $20 \mathrm{~km}$ Early Imperial ERGM shown in table 4 . What is important, however, is that some of these models now include significant attribute related effects. Indeed, these new models show more significant effects than the ERGMs without attributes, indicating that these attributes are of importance and are likely to have influenced the structure and evolution of the visibility networks. These results seem to suggest that the observed network structure cannot be fully understood without reference to three of these attributes: sites on elevations, with Iberian origins, and with an urban status. The only attributed model that does not show any significant attribute effects is the 
transport network model. This indicates that the location of sites along the main road or river networks did not influence (positively or negatively) the emergence of the observed visibility network.

The urban status model has a positive and significant attribute_out-2-star effect, indicating that sites with an urban status have a tendency to visually control surrounding sites, but not as hubs (i.e., their number of outgoing lines of sight is limited). There is also a negative and significant 2-path attribute effect, indicating that sites with an urban status that are visually prominent do not tend to visually control. This suggests a discrepancy between the indegree and outdegree scores for sites with an urban status. Finally, it is particularly interesting to note the significant negative 2path effect of the Iberian $20 \mathrm{~km}$ model, which might be an indication that the role of sites with an urban status was more similar to that of Iberian-period hub sites than that of contemporary sites without an urban status. These results are quite different to those of the exploratory network analysis, which discerned no particularly prominent position for sites with an urban status.

Similar results were obtained for the model with the Iberian origins attribute: sites with Iberian origins that are visually prominent do not tend to have many outgoing lines of sight, while sites with Iberian origins do have a strong tendency to visually control surrounding sites, far more so than all sites in general. These sites with Iberian origins also do not tend to be particularly visually prominent. This is interesting because it indicates that the more recently founded Roman sites and the abandonment of Iberian sites changed the network structure significantly, suggesting different roles for lines of sight in structuring inter-urban interaction. A model including a qualitative assessment of sites located on elevations was also created. This was done largely as a control of the method, since one would expect such a model to deliver significant results given the dominant role attributed to sites on hills and plateau sides as a result of the viewshed approach. The model suggests similar processes to the previous two models: sites on elevations have a very stong tendency towards visual control, there is no real evidence of an exceptional tendency towards visual prominence, and sites on elevations that are visually prominent do not tend to visually control. Finally, there seems to be no indication that sites with any one attribute have a tendency towards reciprocating lines of sight, i.e. sites with an urban status, Iberian origins or located on elevations are not inter-visible more frequently than one would expect in random processes. 
The results of these ERGMs are highly suspicious given that the exploratory network analysis results were interpreted quite differently, especially for sites with an urban status. Further analysis of these factors is therefore needed. Indeed, our interpretation of how these attributes might have affected the creation of the observed visibility patterns changes dramatically when we create models that combine these attributes. Table 6 shows a model that combines the attributes that have shown significant effects: elevation, Iberian origins and the urban status of particular communities. What is immediately striking is the absence of any significant attribute effects save one: sites on elevations have a tendency of being visually prominent (in2-star). This leads to the not so surprising conclusion that our qualitative observation of sites on elevations better succeeds in explaining the emergence of the Early Imperial visibility patterns than any of the other attributes. We created three additional models in which two of the three attributes are included in turn: status and elevation, status and occupation, elevation and occupation (these models did not show a perfect fit of certain non-modeled features [clustering and triangles], they are therefore not published here and any conclusions drawn from them should be expressed with extreme caution). These again suggest the significance of effects related to sites on elevations and no significant effects were found in the model without the elevation attribute. We can conclude that none of the attributes other than the elevation of sites should be considered of particular interest for explaining the observed visibility patterns.

Table 5. Final ERGMs for the Early Imperial network limited to $20 \mathrm{~km}$ and with arcs $>50 \%$ probability. Each model includes one of four attribute effects: sites on elevation, Iberian origins of site, urban status, and location on river or road network (transport networks). For all circuit configurations $\lambda$ was set to 2 . Asterisks indicate significant effects for which absolute value of estimates are more than twice the standard error. A positive value indicates a tendency towards the creation of this type of configuration, while a negative value indicates a tendency against this configuration.

\begin{tabular}{|c|c|c|c|c|c|c|c|c|}
\hline \multirow{3}{*}{$\begin{array}{r}\text { Configurations } \\
\text { reciprocity }\end{array}$} & \multicolumn{7}{|c|}{ Early Imperial period } & \\
\hline & \multirow{2}{*}{$\begin{array}{r}\begin{array}{c}\text { Sites on } \\
\text { elevation }\end{array} \\
11.88\end{array}$} & \multicolumn{3}{|c|}{ Iberian origins } & \multicolumn{2}{|c|}{ Urban status } & \multicolumn{2}{|l|}{$\begin{array}{l}\text { Transport } \\
\text { networks }\end{array}$} \\
\hline & & $*$ & 11.42 & $*$ & 10.73 & * & 10.06 & $*$ \\
\hline 2-in-star & -6.44 & $*$ & -7.39 & * & -6.98 & $*$ & -5.71 & * \\
\hline 2-out-star & -6.49 & $*$ & -9.22 & $*$ & -3.18 & $*$ & -2.00 & \\
\hline path2 & 4.32 & $*$ & 4.82 & $*$ & 2.67 & * & 1.85 & $*$ \\
\hline Т9(030T) & 0.60 & $*$ & 0.66 & * & 0.59 & $*$ & 0.58 & * \\
\hline Isolates & -1.66 & & -1.92 & $*$ & -1.67 & & -1.34 & \\
\hline AinS & 6.79 & $*$ & 7.68 & $*$ & 7.65 & $*$ & 6.79 & $*$ \\
\hline AoutS & 0.76 & & 1.78 & & 1.98 & & 1.28 & \\
\hline
\end{tabular}




\begin{tabular}{rrrrr} 
AinAout-star & 0.18 & -0.04 & -0.38 & -0.12 \\
attribute_interaction & 0.08 & -0.64 & -0.46 & -0.03 \\
attribute_sender & 0.83 & 0.04 & 0.30 & 0.56 \\
attribute_receiver & 1.77 & 1.37 & 0.53 & -0.30 \\
attribute_in2star & 0.95 & 1.89 & 1.52 & -1.32 \\
attribute_path2 & $-3.39 *$ & $-4.30 *$ & $-2.63 *$ & -0.29 \\
attribute_out2star & $6.25 *$ & $8.98 *$ & $3.28 *$ & 1.26 \\
\hline
\end{tabular}

Table 6. Final ERGM for the Early Imperial network limited to $20 \mathrm{~km}$ and with arcs $>50 \%$ probability. The model includes three attribute effects: sites on elevation, Iberian origins of site and urban status. For all circuit configurations $\lambda$ was set to 2 . Asterisks indicate significant effects for which absolute value of estimates are more than twice the standard error. A positive value indicates a tendency towards the creation of this type of configuration, while a negative value indicates a tendency against this configuration.

\begin{tabular}{|c|c|c|}
\hline Configurations & Estimate & \\
\hline reciprocity & 9.99 & $*$ \\
\hline 2-in-star & -7.70 & $*$ \\
\hline 2-out-star & -1.09 & \\
\hline path2 & 2.05 & \\
\hline 030T & 0.59 & \\
\hline isolates & -1.25 & \\
\hline AinS & 8.24 & $*$ \\
\hline AoutS & 0.55 & \\
\hline AinAout-star & -0.03 & \\
\hline Status_interaction & 0.33 & \\
\hline Elevation_interaction & -0.30 & \\
\hline Occupation_interaction & 0.29 & \\
\hline Status_sender & 0.38 & \\
\hline Elevation_sender & 0.96 & \\
\hline Occupation_sender & -0.62 & \\
\hline Status_receiver & -0.56 & \\
\hline Elevation_receiver & -0.07 & \\
\hline Occupation_receiver & 0.05 & \\
\hline Status_in2star & -0.13 & \\
\hline Elevation_in2star & 3.21 & $*$ \\
\hline Occupation_in2star & -2.12 & \\
\hline Status_path2 & 0.24 & \\
\hline Elevation_path2 & -1.95 & \\
\hline Occupation_path2 & 0.90 & \\
\hline Status_out2star & 0.12 & \\
\hline Elevation_out2star & 0.99 & \\
\hline Occupation_out2star & -0.52 & \\
\hline
\end{tabular}




\section{Discussion and conclusions: towards a better understanding of urban connectivity in Iberian and Roman Southern Spain}

How does this long and rather technical description of results allow us to gain new insights into the structure of and processes governing urban connectivity? A good starting point would be to evaluate how our results compare with our current understanding of Iberian settlement patterns. It has been argued that this pattern consisted of oppida around which rural settlements were positioned, where the intervisibility between oppida and the visual control of the oppidum over rural settlements in its territory can be considered to have been important (Grau Mira 2003, 2005; Ruestes Bitrià 2008). If we only consider lines of sight with high probability, our results only allow us to confirm such a pattern in a few cases. Pancorvo is probably the best example of a fortified urban settlement with strong local $(<20 \mathrm{~km})$ and longdistance $(20-50 \mathrm{~km})$ inter-visibility links with rural settlements in its direct vicinity. It is only visible (not inter-visible with high probability) from one other major Iberian settlement site, Torre del Aguila. Another good example is that of the fortified urban settlement of Castillo de Alhonoz, inter-visible with multiple smaller sites, but mainly over distances less than $20 \mathrm{~km}$. Castillo de Alhonoz is not inter-visible with any other major Iberian sites. Finally the major settlement of Vico (probably related to nearby Montemolín) is inter-visible with three smaller sites over short distances and with five over more than $20 \mathrm{~km}$ distance. It is important to note that all three of these sites are located in parts of the study area with high densities of sites; these dense clusters might well give us a clue about the territories of which these settlements may have acted as some kind of political or aristocratic focus. However, the pattern of intervisible major settlement sites is even less obvious from our results. There is just one example when we only consider high probability lines of sight shorter than 20km: El Nuño - Alamillo. There are no additional examples when considering lines of sight between 20 and $50 \mathrm{~km}$.

However, it would be wrong to argue against inter-visibility as an important feature of the Iberian settlement pattern. When we consider the position of sites other than the major settlement sites, we notice that overall only a limited proportion of them are not part of the visibility network (Fig. 11) and the ERGMs indicate a tendency for sites to be integrated within the network (Table 4). A rather high proportion of lines of sight has a probability of $50 \%$ or over (Fig. 8) and most 
exploratory network measures, both global and local, are indicative of an integrated and dense visibility network with a high number of hubs (in particular Porcún I, Cerro del Manzano, Morón de la Frontera and San Pedro I: very little is known of the Iberian period layout for most of these). We therefore argue against an exclusive focus on the inter-visibility patterns of the major settlement sites, a research bias that might obscure the potentially interesting role that is played by lines of sight connecting rural settlements.

We could interpret this limited inter-visibility between the larger settlements and the rare occurrence of these sites exercising visual control over surrounding rural settlements in light of Grau Mira's (2005) observation for Late Eastern Iberia ( $3^{\text {rd }} \mathrm{c}$. BC). In comparing these to the Classical Iberian period $\left(4^{\text {th }} \mathrm{c} . \mathrm{BC}\right)$ he observed a more dispersed settlement pattern and the disintegration of inter-visibility between settlements. Sadly our current dataset and coarse chronology do not allow a comparison between these different Iberian periods. The ERGMs, however, do suggest that the appearance of highly visible settlements exercising visual control over surrounding settlements, and a tendency for sites to be integrated in the visibility network are significant features of the possible processes leading to the Iberian settlement pattern. We argue that the observed Iberian visibility networks have a structure that facilitates mainly local visual control and communication, as well as occasional signaling and control over greater distance. These features are only possible thanks to the existence of hubs that are inter-visible with a high number of sites and hold the potential of sharing information or exercising control between the dense local clusters of sites. As Grau Mira argues, the role of oppida (akin to our major settlement sites) might have diminished although in some cases the typically hierarchical settlement pattern of oppida surrounded by rural settlements linked by inter-visibility is still clearly present. Moreover, since our settlement dataset is more complete for the larger settlements than for smaller rural settlements, we believe the identification of additional rural settlements through future fieldwork will emphasize this structure of inter-visible clusters even more.

This is the settlement pattern that confronted the Romans when they arrived in this part of Iberia in the late $3^{\text {rd }} \mathrm{c}$ BC. The more dispersed settlements and decrease in inter-visibility observed by Grau Mira for Eastern Iberia might imply a change in the structure and function served by lines of sight between urban settlements. This study has aimed at understanding this structure and its function in more detail in the rather 
different cultural context of south-western Iberia, and a number of general conclusions can be drawn. Firstly, in no way does the changing structure of visibility patterns in Roman times indicate a clean break with the preceding Iron Age. This is most clear in the structural similarity of Republican and Early Imperial period networks to those of the Iberian period. We also observed some very similar tendencies towards certain configurations in the $<20 \mathrm{~km}$ ERGMs of these periods. Secondly, there are also some clear differences between all periods and it would be equally wrong not to emphasize these. Only the Iberian and Republican ERGMs of short-distance arcs show a tendency against isolated settlements and a strong tendency towards hubs with a high number of lines of sight. Moreover, the exploratory network analysis shows a gradual disintegration of that visibility network through time, resulting in a highly fragmentary and low-density network in the Middle and Late Imperial periods. The communication function of the Roman inter-visibility network was strongly affected by the discontinuous occupation of the major settlement hubs in the Iberian network (e.g., Pancorvo and Tejada la Vieja). Thirdly, we noticed that through time an increasing proportion of lines of sight were shorter than $20 \mathrm{~km}$. This suggests that the importance of long-distance inter-visibility diminished in favour of short-distance inter-visibility. Fourthly, a few factors that were no doubt crucial for understanding Roman inter-urban connectivity, such as the location of towns on transport networks or their urban status, cannot be considered fundamental in understanding the processes giving rise to Early Imperial visibility networks. Moreover, the ERGMs suggested that the role of towns with Iberian origins in shaping these Early Imperial visibility patterns (for example as visual focal points for new settlements) should not be over-emphasized, no doubt due to the discontinuity in occupation of Iberian-period hubs.

These general statements do tend to tip the balance more in the direction of a disintegration of the visibility networks in Roman times. But rather than direct disintegration in post-Iberian periods, we believe these results should be interpreted initially as gradual changes in the role of visibility in structuring inter-settlement interactions, possibly followed by disintegration. Both the ERGMs and the exploratory network analysis identified the importance of hubs of a lower degree, which could have taken over the pivotal role played by Iberian settlement hubs. Indeed, many of these low degree Iberian hubs were probably rural settlements that continued in occupation throughout the Roman period, such as Cerro del Bollo; 
Morón de la Frontera, however, was a major settlement that continued as a Roman town. An example of an Iberian fortified settlement that retains its hub-like function until the Early Imperial period is Mesa del Almendro. The increased proportion of short-distance lines of sight from the Early Imperial period onwards (largely caused by the disappearance of Iberian settlements visible over long distances) creates a pattern of small pockets of local inter-visibility, mainly in the areas where we identified a high level of inter-visibility in the Iberian period, allowing for the possibility that these lines of sight continued to function as media for local control and communication. While key Roman settlements along the navigable part of the Guadalquivir are hardly inter-visible (although in some cases we did identify chains of high probability inter-visibility along the river: e.g., Alcolea del Rio - Cantillana), the Via Augusta does cross through areas between Écija and Carmona that are highly visible from many sites (as identified by cumulative viewsheds not presented here, see Brughmans 2014). However, the degree of disintegration is much more pronounced for the Middle and Late Imperial periods.

Grau Mira (2005, p. 332) states that "The Iberian oppida were the spatial manifestation of an economic and socio-political model of control maintained by an aristocratic elite over an extensive peasant base living in rural sites." The changes in the settlement pattern in our study area throughout the Roman period could be considered to reflect a similar phenomenon, in the rather different cultural context of south-western Spain, of a move away from this Iberian model. However, this was a gradual process and the Republican period visibility network in particular should be considered a reflection of a very slow transition to a different model. Such new sociopolitical models should probably be understood in terms of urban settlement location close to transport networks, agrarian products, and minerals, or their integration within the wider Roman administrative system, possibly reflected by the urban status of some communities. The ERGMs allowed us to confront different aspects of settlement location, but the results indicated these factors did not necessarily influence each other.

This study has not revealed alternative factors that might help explain the Roman period inter-visibility structure among the few tested factors, but it did identify changes in its structure and indications of its changing role. If anything, this study has shown that the core of the Iberian inter-visibility network initially persisted but possibly played a different role within a different socio-political model. We 
believe this generalizing picture can be refined by focusing future work on smaller parts of the study area and by considering evidence for other influential factors in the Roman period, for which exploratory network analysis and ERGMs are not necessarily the best approaches. We have discussed in detail a critical and innovative network approach that was developed to answer a particular archaeological research question. We believe this approach has allowed us to gain a critical understanding of the nature and limitations of our data, to be aware of the processes it might suggest as well as explore the implications of such processes. We also expressed caution with pushing our interpretations of these statistical models too far. As we have shown, different combinations of attributes in the models can lead to wildly different results. Every aspect of this combined network approach always requires a recontextualisation within its cultural and historical context before the significance of its results become clear.

Future more local case studies should take the known area of occupation of sites into account and use multiple viewer locations (e.g., Garrido González 2011) preferably with a higher resolution DEM, to avoid missing key inter-visibility patterns A good example of this is the line of sight we observed in our visits to the study area between Castillo de Mulva and Carmona were not picked up by the probable viewsheds, as a result of our decision to select one observer location on the southwestern side of Carmona. This also emphasizes the need in future local studies to compare these computationally derived lines of sight with those that project members observed and recorded in the study area. One way in which a network approach can still offer new information in such future local studies is through representing major Iberian settlements and key Roman urban settlements as egonetworks (Marsden 2002), where particular local patterns of inter-urban interaction can be represented and compared. Comparative studies exploring the differences in visibility patterns observed in different study areas also offer a particularly promising way forward (e.g., Moreno Escobar 2014). In future work we will also move away from the abstract space represented by the ERGMs and aim to simulate the same hypotheses within this particular landscape (i.e. including topography as a constraint in the ERGMs). This will allow us to answer the question of how likely it is for the observed visibility network to emerge by chance in this particular landscape. The models presented here will allow us to focus this future work on the identified range of models with significant effects. However, this work is dependent on 
methodological developments in ERGMs. Finally, we will compare the changes in visibility patterns with changes in the distribution of material culture in order to better place these results in a large-scale framework for the study of Urban Connectivity in Iron Age and Roman Southern Spain.

\section{Acknowledgments}

The 'Urban Connectivity in Iron Age and Roman Southern Spain' project directed by Prof. Simon Keay and Dr. Graeme Earl was funded by the UK Arts and Humanities Research Council (AHRC) between 2002 and 2005 with subsequent support by the University of Southampton and institutions in Seville, notably the Departamento de Prehistoria I Arqueología de la Universidad de Sevilla and the Delegación de Cultura de la Junta de Andalucía. We would like to thank Cat Cooper for help with the maps, Leticia López Mondéjar for bibliographical suggestions, Matt Peeples for suggestions concerning sensitivity analyses, Iza Romanowska, Mari Carmen Moreno Escobar, Viviana Amati, two-peer reviewers, and the editors of this special issue for helpful comments on different versions of the manuscript, Pablo Garrido González for expert advice on the study area, and Dave Wheatley for his ArcGIS Python script.

\section{Bibliography}

Anderson, C. J., Wasserman, S., \& Crouch, B. (1999). A p* primer: logit models for social networks. Social Networks, 21(1), 37-66. doi:10.1016/S03788733(98)00012-4

Brughmans, T. (2014). Evaluating network science in archaeology. A Roman archaeology perspective. Unpublished $\mathrm{PhD}$ thesis. University of Southampton.

Brughmans, T., Keay, S., \& Earl, G. P. (2014). Introducing exponential random graph models for visibility networks. Journal of Archaeological Science, 49: 442-54. doi: 10.1016/j.jas.2014.05.027

Collar, A., Coward, F., Brughmans, T., \& Mills, B. J. (2015). Networks in Archaeology: Phenomena, Abstraction, Representation. Journal of Archaeological Method and Theory. 
Conolly, J., \& Lake, M. (2006). Geographical information systems in archaeology. Cambridge; New York: Cambridge University Press. Retrieved from http://www.loc.gov/catdir/enhancements/fy0665/2006296605-d.html

Corzo, R. S., \& Toscano, M. S. G. (1992). Las Vias Romanas de Andalucía. Sevilla: Consejería de Obras Públicas y Transportes, Junta de Andalucía.

Crema, E. R., Bevan, A., \& Lake, M. W. (2010). A probabilistic framework for assessing spatio-temporal point patterns in the archaeological record. Journal of Archaeological Science, 37(5), 1118-1130. doi:10.1016/j.jas.2009.12.012

Cunliffe, B. (1995). Diversity in the landscape: the geographical background to urbanism in Iberia. In B. Cunliffe \& S. Keay (Eds.), Social complexity and the development of towns in Iberia. From the Copper Age to the second century AD (pp. 5-28). Oxford: The British Academy.

Daraganova, G., Pattison, P., Koskinen, J., Mitchell, B., Bill, A., Watts, M., \& Baum, S. (2012). Networks and geography: Modelling community network structures as the outcome of both spatial and network processes. Social Networks, 34(1), 6-17. doi:10.1016/j.socnet.2010.12.001

Davidson, D. A. (1979). The Orcadian environment and cairn location. In C. Renfrew (Ed.), Investigations in Orkney (pp. 7-20). London: Thames and Hudson.

De Montis, A., \& Caschili, S. (2012). Nuraghes and landscape planning: Coupling viewshed with complex network analysis. Landscape and Urban Planning, 105(3), 315-324. doi:10.1016/j.landurbplan.2012.01.005

Domergue, C. (1990). Les mines de la Péninsule Ibérique dans l'antiquité romaine. Rome: École Française de Rome.

Earl, Graeme \& Keay, Simon (2007) Urban connectivity of Iberian and Roman towns in southern Spain: a network analysis approach. In Jeffrey T. Clark and Emily M. Hagemeister (eds) Digital Discovery: Exploring New Frontiers in Human Heritage. CAA 2006. Computer Applications and Quantitative Methods in Archaeology. Proceedings of the 34th Conference, Fargo, United States, April 2006.Budapest:'Archaeolingua. (ISBN 978-963-8046-90-1)

Erdős, P., \& Rényi, A. (1959). On random graphs. Publicationes Mathematicae, 6, 290-297.

Fear, A. T. (1996). Rome and Baetica: urbanization in Southern Spain c. 50 $B C-A D$ 150. Oxford: Oxford University Press. 
Fisher, P. F. (1995). An exploration of probable viewsheds in landscape planning. Environment and Planning B: Planning and Design, 22, 527-546.

Fisher, P. F. (1994). Probable and fuzzy models of the viewshed operation. In M. F. Worboys (Ed.), Innovations in GIS: selected papers from the First national Conference on GIS Research UK (pp. 161-175). London: Taylor \& Francis.

Fisher, P. (1992). First experiments in viewshed uncertainty: simulating fuzzy viewsheds. Photogrammetric Engineering and Remote Sensing, 58(3), 345-352.

Fraser, D. (1983). Land and society in Neolithic Orkney. BAR British Series 117. Oxford: Archaeopress.

Garrido González, P. (2011). La Ocupación Romana del Valle del Guadiamar y la conexión Minera. Unpublished PhD thesis. Sevilla, Universidad de Sevilla. Retrieved from http://fondosdigitales.us.es/tesis/tesis/1564/la-ocupacion-romana-delvalle-del-guadiamar-y-la-conexion-minera/

Grau Mira, I. (2005). Romanization in Eastern Spain: a GIS approach to Late Iberian Iron Age landscape. In J.-F. Berger, F. Bertoncello, F. Braemer, D. Gourguen, \& M. Gazenbeek (Eds.), Temps et espaces de l'homme en société, analyses et modèles spatiaux en archéologie. XXVième rencontres internatioales d'archéologie et d'histoire d'Antibes (pp. 325-334). Antibes: Éditions APDCA.

Grau Mira, I. (2004). La construcción del paisaje ibérico: aproximación SIG al territorio protohistórico de la Marina Alta. SAGVNTVN (P.L.A.V.), 36, 61-75.

Grau Mira, I. (2003). Settlement Dynamics and Social Organization in Eastern Iberia during the Iron Age (Eighth-Second Centuries BC). Oxford Journal of Archaeology, 22(3), 261-279. doi:10.1111/1468-0092.00187

Keay, S. (1998a). Introduction: the archaeology of Early Roman Baetica. In S. Keay (Ed.), The archaeology of Early Roman Baetica. Journal of Roman Archaeology Supplement Series 29 (pp. 11-22). Portsmouth - Rhode Island: Journal of Roman Archaeology.

Keay, S. (1998b). The development of towns in Early Roman Baetica. In S. Keay (Ed.), The archaeology of Early Roman Baetica. Journal of Roman Archaeology Supplement Series 29 (pp. 55-86). Portsmouth - Rhode Island.

Keay, S. (1998c). The archaeology of Early Roman Baetica. Portsmouth Rhode Island: Journal of Roman Archaeology. 
Keay, S., \& Earl, G. P. (2011). Towns and territories in Roman Baetica. In A. Bowman \& A. Wilson (Eds.), Settlement, urbanization, and population (pp. 276316). Oxford: Oxford University Press.

Keay, S., \& Earl, G. (2006). Inscriptions and Social Networks in western Baetica. In A. Sartori \& A. Valvo (Eds.), Hiberia Italia, Italia-Hiberia. HiberiaItalia, Italia-Hiberia: Convegno Internazionale di Epigrafia e Storia Antica Milan, Italy, Cisalpino (Acta et Studia 2) (pp. 269-290). Milan: Cisalpino.

Knapp, R. (1983). Roman Cordoba. History and archaeology. Berkeley: University of California publications.

Koskinen, J., \& Daraganova, G. (2013). Exponential random graph model fundamentals. In D. Lusher, J. Koskinen, \& G. Robins (Eds.), Exponential Random Graph Models for Social Networks (pp. 49-76). Cambridge: Cambridge university press.

Le Roux, P. (1995). Romains d'Espagne. Cités et politique dans les provinces. Paris.

Llobera, M. (2007). Reconstructing visual landscapes. World Archaeology, 39(1), 51-69. doi:10.1080/00438240601136496

Llobera, M. (2003). Extending GIS-based visual analysis: the concept of visualscapes. International Journal of Geographical Information Science, 17(1), 2548. doi:10.1080/13658810210157732

Lusher, D., Koskinen, J., \& Robins, G. (2013). Exponential Random Graph Models for Social Networks. Cambridge: Cambridge university press.

Lusher, D., \& Robins, G. (2013). Formation of social network structure. In D. Lusher, J. Koskinen, \& G. Robins (Eds.), Exponential Random Graph Models for Social Networks (pp. 16-28). Cambridge: Cambridge University Press.

Marsden, P. V. (2002). Egocentric and sociocentric measures of network centrality. Social Networks, 24(4), 407-422.

Mayoral Herrera, V. (2004). Paisajes agrarios y cambio social en Andalucía oriental entre los periodos ibérico y romano. Anejos de Aespa XXXI. Madrid: CSIC.

Mitcham, J. (2002). In search of a defensible site: a GIS analysis of Hampshire hillforts. In D. Wheatley, G. Earl, \& S. Poppy (Eds.), Contemporary Themes in Archaeological Computing (pp. 73-79). Oxford: Oxbow. 
Moreno Escobar, M. C. (2014). Patrones de asentamiento en la Bética romana. Un estudio del proceso de romanización desde el análisis arqueológico espacial. Unpublished Doctoral thesis. Universidad Pablo de Olavide.

Newman, M. E. J. (2010). Networks: an introduction. Oxford: Oxford University Press.

Peeples, M. A., \& Roberts, J. M. (2013). To binarize or not to binarize: relational data and the construction of archaeological networks. Journal of Archaeological Science, 40(7), 3001-3010. doi:10.1016/j.jas.2013.03.014

Ponsich, M. (1991). Implantation rurale antique sur le bas-Guadalquivir T. 4. Madrid: Laboratoire d'archéologie de la Casa de Velázquez.

Ponsich, M. (1987). Implantation rurale antique sur le bas-Guadalquivir T. 3. Madrid.

Ponsich, M. (1979). Implantation rurale antique sur le Bas-Guadalquivir. T. 2, La Campana, Palma del Rio, Posadas. Paris: E. de Boccard.

Ponsich, M. (1974). Implantation rurale antique sur le Bas-Guadalquivir. T. 1. Madrid: Laboratoire d'archéologie de la Casa de Velázquez.

Richardson, J. S. (1996). The Romans in Spain. Oxford: Blackwell. Roos, A. M., Schulz, H. D., Arteaga Matute, O., \& Schulz, H. (1995). El problema del "Lacus Ligustinus". Investigaciones geoarqueológicas en torno a las marismas del bajo Guadalquivir. In Actas del Congreso Conmemorativo del $\mathrm{V}$ Symposium Internacional de Prehistoria Peninsular. Tartessos: 25 años después, 1968-1993 (pp. 99-135). Jerez de la Frontera.

Ruestes Bitrià, C. (2008). A Multi-technique GIS Visibility Analysis for Studying Visual Control of an Iron Age Landscape. Internet Archaeology, 23, http://intarch.ac.uk/journal/issue23/4/index.html.

Ruiz Rodríguez, A. (1997). The Iron Age Iberian peoples of the upper Guadalquivir valley. In M. Díaz-Andreu \& S. Keay (Eds.), The Archaeology of Iberia. The dynamics of change (pp. 175-191). London - New York: Routledge.

Ruiz Rodríguez, A., \& Molinos, M. (1993). Iberos. Análisis arqueológico de un proceso histórico. Barcelona: Crítica.

Shemming, J., \& Briggs, K. (2013). Anglo-saxon communication networks. http://keithbriggs.info/AS_networks.html [accessed 4-10-2013]

Sillières, P. (1991). Les voies de communication de l'Hispanie méridionale. Paris: Diffusion De Boccard. 
Swanson, S. (2003). Documenting prehistoric communication networks: A case study in the Paquimé polity. American antiquity, 68(4), 753-767.

Thomas, J. (2004). Archaeology and Modernity. London: Routledge.

Thomas, J. (1993). The politics of vision and the archaeologies of landscape. In B. Bender (Ed.), Landscapes: Politics and Perspectives (pp. 1-19). Oxford: Berg.

Tilley, C. Y. (1994). A Phenomenology of Landscape. Oxford: Berg.

Tovar, A. (1974). Iberische Landeskunde. 2. Teil: Die Völkerunddie Städte des antiken Hispanien, Band I: Baetica. Baden-baden: Valentin Koerner.

Wasserman, S., \& Faust, K. (1994). Social network analysis : methods and applications. Cambridge: Cambridge University Press.

Wasserman, S., \& Pattison, P. (1996). Logit models and logistic regressions for social networks: I. An introduction to Markov graphs and p*. Psychometrika, 61(3), 401-425.

Wheatley, D. W. (1995). Cumulative Viewshed Analysis: a GIS-based method for investigating intervisibility, and its archaeological application. In G. Lock \& Z. Stančič (Eds.), Archaeology and Geographical Information Systems: a European Perspective (pp. 171-186). London: Taylor \& Francis.

Wheatly, D., \& Gillings, M. (2002). Spatial Technology and Archaeology. The archaeological applications of GIS. The Archaeological Applications of GIS. London - New York: Taylor \& Francis.

Wheatley, D., \& Gillings, M. (2000). Vision , Perception and GIS : developing enriched approaches to the study of archaeological visibility. In G. R. Lock (Ed.), Beyond the Map: Archaeology and Spatial Technologies (pp. 1-27). Amsterdam: IOS Press.

Wood, J. (1996). The Geomorphological Characterisation of Digital Elevation Models. Unpublished PhD Thesis. Leicester. 